\title{
The analysis of thermoplastic characteristics of special polymer sulfur composite
}

Received: 28 April 2016 / Accepted: 24 June 2016 / Published online: 13 July 2016

(C) The Author(s) 2016. This article is published with open access at Springerlink.com

\begin{abstract}
Specific chemical environments step out in the industry objects. Portland cement composites (concrete and mortar) were impregnated by using the special polymerized sulfur and technical soot as a filler (polymer sulfur composite). Sulfur and technical soot was applied as the industrial waste. Portland cement composites were made of the same aggregate, cement and water. The process of special polymer sulfur composite applied as the industrial waste is a thermal treatment process in the temperature of about $150-155^{\circ} \mathrm{C}$. The result of such treatment is special polymer sulfur composite in a liquid state. This paper presents the plastic constants and coefficients of thermal expansion of special polymer sulfur composites, with isotropic porous matrix, reinforced by disoriented ellipsoidal inclusions with orthotropic symmetry of the thermoplastic properties. The investigations are based on the stochastic differential equations of solid mechanics. A model and algorithm for calculating the effective characteristics of special polymer sulfur composites are suggested. The effective thermoplastic characteristics of special polymer sulfur composites, with disoriented ellipsoidal inclusions, are calculated in two stages: First, the properties of materials with oriented inclusions are determined, and then effective constants of a composite with disoriented inclusions are determined on the basis of the Voigt or Rice scheme. A brief summary of new products related to special polymer sulfur composites is given as follows: Impregnation, repair, overlays and precast polymer concrete will be presented. Special polymer sulfur as polymer coating impregnation, which has received little attention in recent years, currently has some very interesting applications.
\end{abstract}

Keywords Thermoplastic characteristics - Thermoplastic properties - Sulfur composites · Waste of sulfur · Impregnation cement composites

\section{Introduction}

Sulfur composites are high performance thermoplastic composite materials made of sulfur as a binder and technical soot as a filler, at temperature above the hardening point of sulfur $\left(150-160^{\circ} \mathrm{C}\right)$ [1-6].

Using sulfur as a coating protection is based on its physical and chemical characteristics: thermoplastic, chemical passivity, excellent resistance to aggressive agents (mainly acids and salt solutions, but not bases) and hydrophobic properties. Sulfur and technical soot was applied as the industrial waste [5-10].

Sulfur applied as the industrial waste is shown in Fig. 1.

The sulfur composites as the coating protecting are: quick hardening and reaching the required characteristics in only $24 \mathrm{~h}$; high strength and fatigue resistance; very low water permeability; and exceptional resistance

Communicated by Andreas Öchsner.

M. Książek (凶)

Faculty of Civil Engineering, Division of Building Materials, Timber and Monumental Heritage Structures,

Wrocław University of Technology, pl. Grunwaldzki 11, 50-377 Wrocław, Poland

E-mail: ksiazekmariusz@wp.pl 
(a)
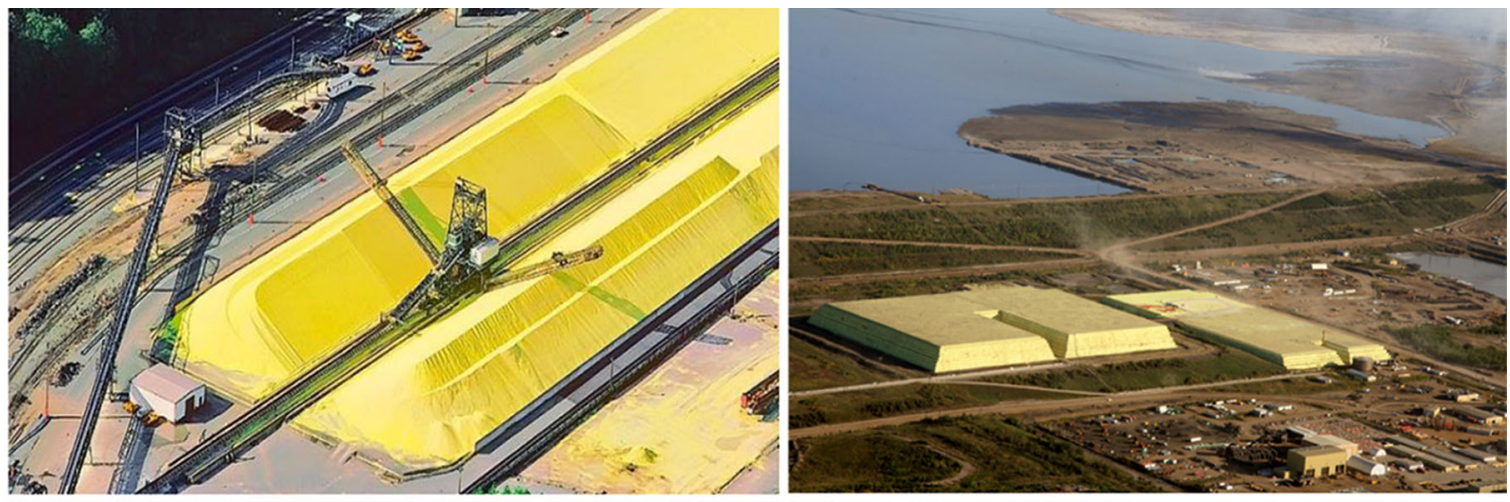

(b)
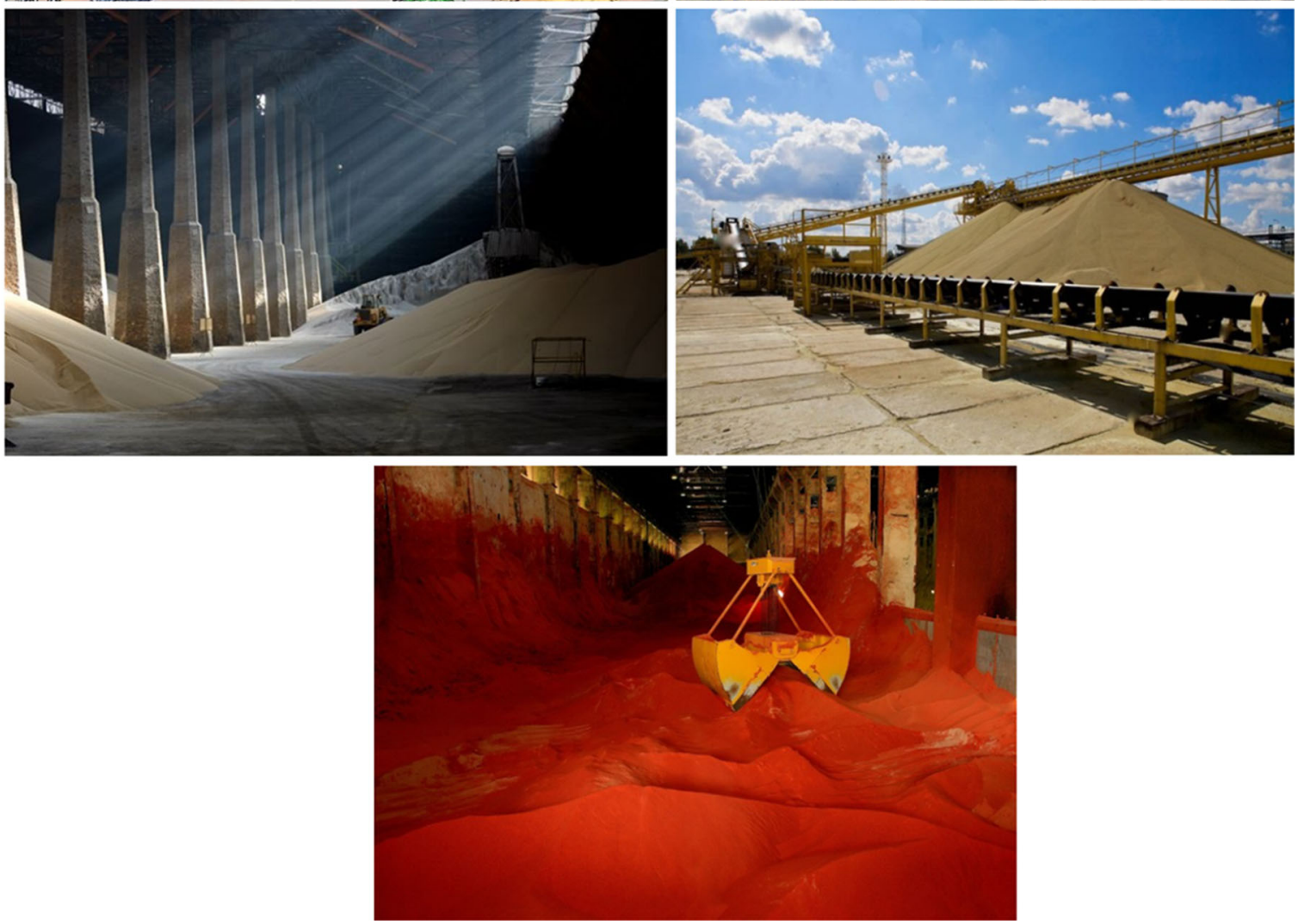

Fig. 1 View of the waste of sulfur $\mathbf{a}$ in Europe, $\mathbf{b}$ in Poland

to acid and salt agents, which allows its use in extremely aggressive environments. It can be produced and installed throughout the year, regardless of weather conditions, and it can be recycled. This material allows utilization of large amounts of sulfur from worldwide oil refineries and metallurgical industries [10-16].

Czarnecki $[4,5]$ and Hoła $[12,16]$ found that the at ambient temperature special sulfur composites applied as the industrial waste crystallize in the rhombic system $(\alpha-\mathrm{S})$. It melts at the temperature $105-110{ }^{\circ} \mathrm{C}$ and crystallizes from this melt to the form of $\beta$-S (monociclic) which changes again to the $\alpha-\mathrm{S}$ at $95-96{ }^{\circ} \mathrm{C}$ (thermoplastic properties) [33-36].

Melted sulfur polymerizes with special polymer coating applied as the industrial waste in the industries objects as discussed and published elsewhere [10-16,19-22]:

- $160^{\circ} \mathrm{C}$ it is brown and indicates increased viscosity,

- between 200 and $250^{\circ} \mathrm{C}$ it is dark brown with high viscosity value,

- $250{ }^{\circ} \mathrm{C}$ depolymerization and diminishing of viscosity begins; at $400^{\circ} \mathrm{C}$ sulfur is very fluid, 
- $444.6{ }^{\circ} \mathrm{C}$ is the temperature of its boiling. The rapid process of cooling sulfur in water changes it from fluid state to an elastic-plastic body, brown-yellow colored. In this state sulfur is composed of two different polymerized forms: $S_{\lambda}$ (yellow) and $S_{\mu}$ (dark red-brown). $S_{\mu}$ has a higher molecular mass [15-20].

Sulfur may be obtained in the colloidal state as discussed elsewhere [35-40]:

- after boiling with water and $\mathrm{Ca}(\mathrm{OH})_{2}$ and precipitation with $\mathrm{HCl}-\mathrm{S}_{\mu}$

- after hydrolysis of alcohol solution $-S_{\lambda}$ [20-26].

Hoła [13-16] and Książek [19-25] found the functional properties of the special polymerized sulfur coating and sulfur polymer based products. Orthorhombic special polymerized sulfur is also subject to deterioration by bacteria, sunlight, very strong alkalies, and thermal fluctuations [25-30].

Czarnecki [4-8] and Hoła [12] found that the polymer cement concretes (PCC) are obtained by adding special polymerized sulfur coating to the concrete mix; they are a diverse set of composites, usually with better consistency of the concrete mix and increased-as compared to the ordinary concrete-tensile strength, as well as many other modified thermoplastic properties [4-8].

Czarnecki [4-8] and Książek [30-36] found that the special polymer sulfur composites-impregnated concretes (PIC) are basically different from all other types of polymer concretes. In this case, the special sulfur polymer is introduced into the hardened cement concrete. The result is an extraordinary increase in the tightness, manifesting itself by tenfold or even twentyfold downfall of the absorbability, from $4 \%$ for unmodified concrete to $0.30-0.16 \%$ for impregnated concrete. The consequence of filling of the pores with special polymer sulfur is also twofold to fourfold increase in compressive strength, twofold to threefold increase in tensile strength and fourfold decrease in the diffusion coefficient. PIC show more than three times lower creep. PIC (concretes impregnated with special polymerized sulfur composite) have very high chemical resistance, significantly decreased penetration of chloride ions and improved frost resistance. Practically, the only disadvantage of PIC is the sudden mode of failure; modulus of elasticity can reach $45 \mathrm{GPa}(45,000 \mathrm{MPa})$. This inconvenience can be eased, to some extent, by introduction of the suitable impregnating copolymers. We can assume, therefore, that we have in disposal the perfect concrete, durable and with excellent technical features. The special sulfur polymer-impregnated concretes (PIC) are not widely implemented. There is a factory producing precast elements of PIC in Japan, manufacturing the pipes and other elements of the underground infrastructure. There is also a company offering the impregnation services in Germany, aimed at conservation of the stone objects. Repairs of the bridge pavements and surfaces of the water dams have been performed in the USA in seventies (Dworshak Dam in Idaho). The repairs consisted in the superficial impregnation of the previously dried concrete to the depth of several $\mathrm{cm}$. The concrete was periodically heavily sprinkled with the special polymerized sulfur composite and spilled with fine-grained sand for limiting the special polymerized sulfur composite evaporation. The prototype machine with suckers was employed on the bridges; the machine sucked out the air from the dried concrete and then force the special polymer sulfur composite into the concrete under pressure [4-8].

Czarnecki [4-8] and Kamiński [17] found that the external surfaces of the concrete are protected with the plastic sheet for avoiding the polymer evaporation. The impregnation is initiated thermally, by steam or immersion in hot special polymerized sulfur composite at the temperature above $80{ }^{\circ} \mathrm{C}$ for several hours. The research works (not numerous presently) are involved with simplification of the technological process. They are aimed at elimination of air sucking, with only necessary preparation by concrete drying and with replacement of the pressure impregnation by gravitational one. The through impregnation of the elements of the thickness up to $10 \mathrm{~cm}$ is possible this way. The process can be intensified to $30 \mathrm{~cm}$ and perhaps even $50 \mathrm{~cm}$ by introduction into the impregnated element with special polymerized sulfur coating the suitably distributed venting ducts. There is also conception of forming the concrete microstructure during prefabrication, increasing the impregnation susceptibility with special polymerized sulfur composite. The above considerations show that the concept of PIC is very attractive regarding the technical properties of the product. The barrier is complicated technological process, almost impossible to perform on the existing objects. The impregnation of precast concrete pipes seems to be the most promising and purposeful [4-8].

Czarnecki [4-8] and Książek [19-25] found that the tremendous increase in properties was offset by the complexities of the impregnation process: drying to remove all of the moisture, evacuating the air, applying the special polymerized sulfur under pressure to fully impregnate the concrete and the application of heat or irradiation to fully polymerize the monomer. To fully impregnate large precast components such as several city collectors, bridge girders, bridge deck slabs, piling and wall panels would require a large, efficient facility that would be difficult to justify unless it could be shown that a market for a large volume of PIC products would be forthcoming. No such facility has ever been developed in the Poland. Until some breakthroughs in 
process technology are realized, there is little likelihood that fully impregnated PIC members will ever become economically feasible. This is unfortunate since PIC has such exceptional strength and durability properties [4-8].

Degradation of cement composites often results in initiation and propagation of microcracks and other microdefects. Microcracks develop because of chemical, physical and mechanical interferences. Numerous researches have proved that the presence of microcracks can significantly influence the mechanical properties of cement composites. Since the control and detection of microcracks are not easy, the formation of microcracks is an essential concern for the durability of cement composites. The prediction of material macroscopic properties requires a method capable of quantifying the material microstructural characteristics

Let us examine representative volume $V$ of the thermoelastic special polymer sulfur composites as randomly inhomogeneous medium, at each point $x^{(1)}$ for which the Duhamel-Neumann law [41] is given by:

$$
\begin{aligned}
& \sigma_{i j}^{(1)}=\lambda_{i j \alpha \beta}^{(1)} \varepsilon_{\alpha \beta}^{(1)}-\beta_{i j}^{(1)} \theta ; \\
& \beta_{i j}^{(1)}=\lambda_{i j m n}^{(1)} \alpha_{m n}^{(1)},
\end{aligned}
$$

the equilibrium equations [41]:

$$
\sigma_{i j, j}=o
$$

and the Cauchy relationship [41]:

$$
\varepsilon_{i j}^{(1)}=1 / 2\left(u_{i, j}^{(1)}+u_{i, j}^{(1)}\right),
$$

are valid, where $\sigma_{i j}$ and $\varepsilon_{i j}$ are stress and strain tensors, $\lambda_{i j \alpha \beta}$ is the tensor of elastic constants, $\beta_{i j}$ and $\alpha_{m n}$ are tensors of the coefficients of temperature stresses and the coefficients of linear thermal expansions, respectively, $\theta$ is the temperature increase, and $u_{i}$ are the displacements [41].

When the representative volume is acted upon by a uniform load and heating, the stresses and strains that develop within this body form statistically homogeneous random fields satisfying the property of ergodicity. This makes it possible to replace the operation of averaging over an ensemble of realizations. For macroscopic fields, we can write [41]:

$$
\left\langle\sigma_{i j}\right\rangle=\lambda_{i j \alpha \beta}^{*}\left\langle\varepsilon_{\alpha \beta}\right\rangle-\beta_{i j}^{*} \theta ; \beta_{i j}^{*}=\lambda_{i j m n}^{*} \alpha_{m n}^{*},
$$

where $\lambda_{i j m n}^{*}$ and $\alpha_{m n}^{*}$ are tensors of the effective elastic constants and the temperature expansions coefficients [41].

Consider a special polymer sulfur composites reinforced by randomly distributed and randomly directed ellipsoidal inclusions. This composite may be regarded as a set of subsystems; each subsystem consists of a composite with oriented inclusions, and the symmetry axes of which are directed in a certain manner relative to the initial coordinate system of the composite as a whole. Consider such subsystem and suppose that the inclusions are orthotropic, oriented ellipsoids and the geometric axes of the ellipsoids coincide with the orthotropy axes of the thermoelastic modulus tensor. The orientation of the coordinate axes of the subsystem $x_{1}, x_{2}, x_{3}$ relative to the basic coordinate system of the material $x_{1}^{\prime}, x_{2}^{\prime}, x_{3}^{\prime}$ will be described by directional cosines as follows [41]:

$$
x_{i}^{\prime}=a_{i k} x_{k} . \quad[41]
$$

The directional cosines may be expressed in terms of Euler angles as follows [41]:

$$
\begin{aligned}
& a_{11}=\cos \psi \cos \varphi-\cos \theta \sin \psi \sin \varphi ; \quad a_{21}=-\cos \psi \sin \varphi-\cos \theta \sin \psi \cos \varphi ; \\
& a_{31}=\sin \theta \sin \psi ; \quad a_{12}=\sin \psi \cos \varphi+\cos \theta \cos \psi \sin \varphi ; \quad a_{13}=\sin \theta \sin \varphi ; \\
& a_{22}=-\sin \psi \sin \varphi+\cos \theta \cos \psi \cos \varphi ; \quad a_{32}=-\sin \theta \cos \psi ; \\
& a_{23}=\sin \theta \cos \varphi ; \quad a_{33}=\cos \theta ; \quad(0 \leq \theta<\pi ; \quad 0 \leq \varphi<2 \pi ; 0 \leq \psi<2 \pi) .
\end{aligned}
$$

Then, it follows from the conversion formulas for the components of tensors of four and second ranks on transition from coordinate system $x_{i}$ to $x_{i}^{\prime}$ that [41]:

$$
\lambda_{i j \alpha \beta}^{* \prime}=a_{i m} a_{j n} a_{\alpha k} a_{\beta l} \lambda_{m n k l}^{*} ; \beta_{i j}^{* \prime}=a_{i m} a_{j n} \beta_{m n}^{*} .
$$


Then, introducing the distribution function that describes the spread of the coordinate axes of the subsystems relative to the Euler angles $f(\theta, \varphi, \psi)$, the mean value of the thermoplasticity coefficients may be written in the form of an integral with respect to all three angles [41]:

$$
\begin{aligned}
\left\langle\lambda_{i j k l}^{*}\right\rangle & =\frac{1}{8 \pi^{2}} \int_{0}^{\pi} \int_{0}^{2 \pi} \int_{0}^{2 \pi} f(\theta, \varphi, \psi) \lambda_{i j k l}^{* \prime}(\theta, \varphi, \psi) \sin \theta d \theta d \varphi d \psi \\
\left\langle\beta_{i j}^{*}\right\rangle & =\frac{1}{8 \pi^{2}} \int_{0}^{\pi} \int_{0}^{2 \pi} \int_{0}^{2 \pi} f(\theta, \varphi, \psi) \beta_{i j}^{* \prime}(\theta, \varphi, \psi) \sin \theta d \theta d \varphi d \psi \text {. [41]. }
\end{aligned}
$$

Thus, the approximate determination of the thermoplastic constants of the special polymer sulfur composites may be divided two stages: First, the properties of the special polymer sulfur composites with oriented and randomly distributed inclusions are determined; then the properties of the subsystems oriented in a certain manner, relative to the axes of the basic coordinate system, are calculated, and the effective properties of the whole system are determined by using the specified distribution function. The first stage is based on a model of the special polymer sulfur composites of stochastic structure reinforced by oriented ellipsoids. The effective properties of this special polymer sulfur composites, with orthotropic components, may be determined by using the method of conditional moment functions, and the second stage is based on the Voigt scheme, as outlined above, or on the Rice scheme (the elastic-pliability and the coefficients of linear thermal expansions tensors are averaged) [41].

In this case, Eq. (9) takes the form [41]:

$$
\begin{aligned}
\left\langle S_{i j k l}^{*}\right\rangle & =\frac{1}{8 \pi^{2}} \int_{0}^{\pi} \int_{0}^{2 \pi} \int_{0}^{2 \pi} f(\theta, \varphi, \psi) S_{i j k l}^{* \prime}(\theta, \varphi, \psi) \sin \theta d \theta d \varphi d \psi ; \\
\left\langle\alpha_{i j}^{*}\right\rangle & =\frac{1}{8 \pi^{2}} \int_{0}^{\pi} \int_{0}^{2 \pi} \int_{0}^{2 \pi} f(\theta, \varphi, \psi) \alpha_{i j}^{* \prime}(\theta, \varphi, \psi) \sin \theta d \theta d \varphi d \psi,
\end{aligned}
$$

where $S_{i j k l}^{*}=\lambda_{i j k l}^{*-1}$, and $S_{i j k l}^{* \prime}$ is determined by analogy with Eq. (8) [41].

The special polymer sulfur composites applied as the industrial waste technology sets new standards and allows you to use sulfur concrete extensively in the road construction industry. Considerable savings owing to longer life and resistance to corrosion plus the thickness of the road base layer are self-evident especially in regions with harsh climate, such as Siberia, Far East and the north of Russia and Canada as discussed elsewhere [19-25].

The special polymer sulfur composites applied as the industrial waste material technology means not only advantages for the user but also benefits for the environment, including low $\mathrm{CO}_{2}$ emission and low energy input for the process of waste stabilization and product prefabrication. Virtually waste-free, this technology does not require using water, and every product is $100 \%$ recyclable without any loss or waste as discussed and published elsewhere [30-35,40-46].

Benefits of the special polymer sulfur composites Technology user as discussed elsewhere [17-20,42-46].

Functional properties of the special polymer sulfur composites and sulfur polymer based products as discussed and published elsewhere [16-30,40-46].

\section{Materials and methods: research procedure}

\subsection{Materials}

The initial materials used in technological procedure for special sulfur composite production were: sulfur binder applied as industrial waste (Fig. 1) and technical soot as a filler. Also technical soot applied as industrial waste. 
(a)
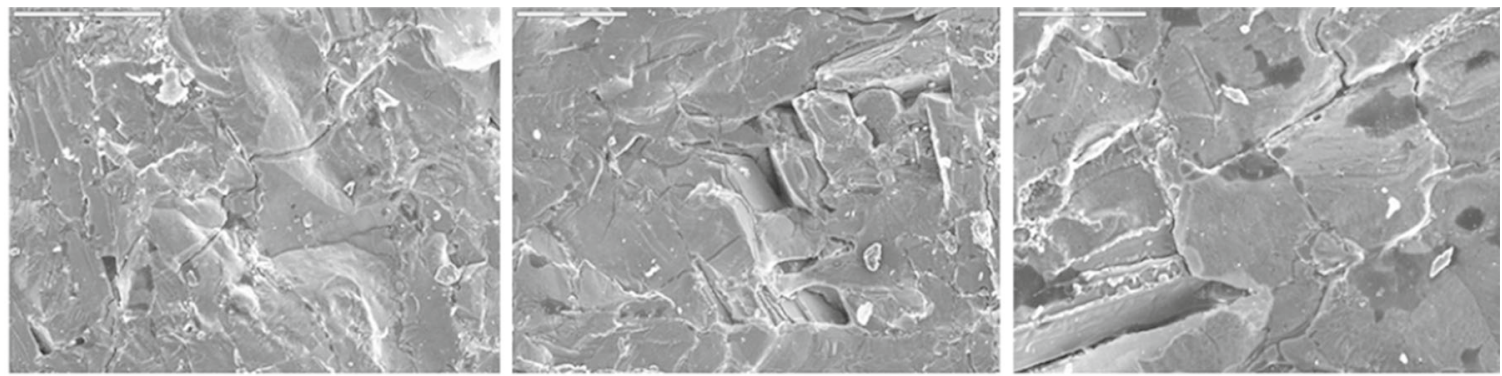

(b)
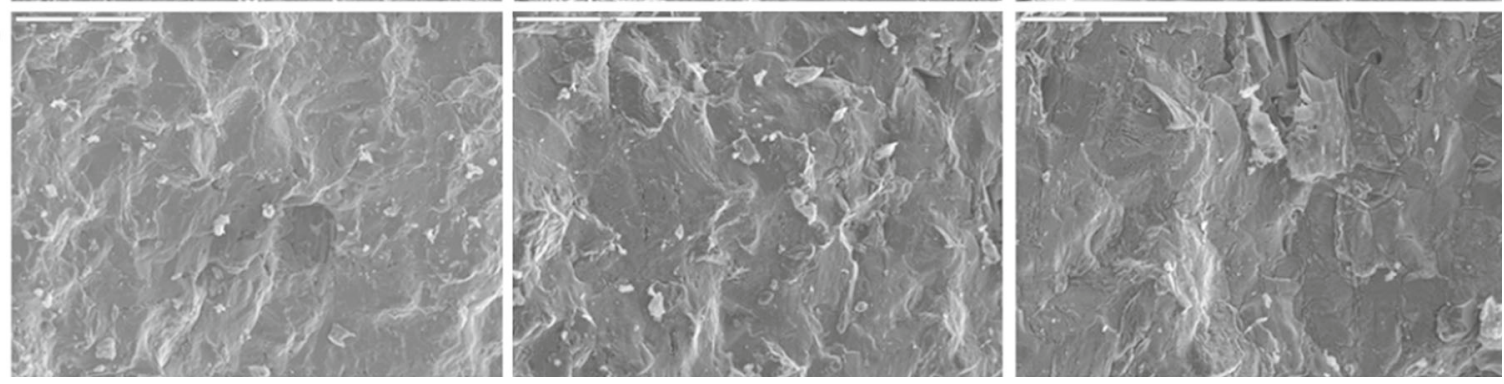

Fig. 2 Structure of sulfur: a elementary, $\mathbf{b}$ modified

Table 1 Composition of sulfur applied as the industrial waste

\begin{tabular}{lll}
\hline & Component & Content $(\%)$ \\
\hline 1 & Fine sulfur, $\mathrm{S}_{8}$ & 97.86 \\
2 & Oil & 2.13 \\
3 & Ash & 0.01 \\
4 & Leaven as $\mathrm{H}_{2} \mathrm{SO}_{4}$ & 0.001 \\
5 & Piece volatile & 0.02 \\
6 & Remainder on the sieve $0.063 \mathrm{~mm}$ & 0.01 \\
\hline
\end{tabular}

\subsubsection{Sulfur}

At first, the elementary sulfur was used as a binder in production of special sulfur composite. However, despite excellent mechanical properties after preparation, the samples exhibited low stability, so spalling and failure occurred after a short period [16,25-30].

The development of modified sulfur binder contributed to better endurance of sulfur composite, which led to its primary use for road construction and repairing, and as a building material $[19,20]$.

Sulfur, the basic component for a modified sulfur binder, originates from the technical soot. Because of the importance of preparing the sulfur composite with modified sulfur, both elementary and the obtained modified sulfur were investigated by scanning electron microscope (SEM), type JEOL JSM-5800 with EDX, Fig. 2, and their microstructures were analyzed according to the literature [19-25].

The results showed that the elementary sulfur was composed of dense orthorhombic crystals of alpha form $\left(S_{\alpha}\right)$, Fig. 2a, while modified sulfur consists of plate monoclinic crystals of beta form $\left(S_{\beta}\right)$, partially polymerized in zigzag chains, Fig. $2 \mathrm{~b}$. Therefore, it was proved that modification of sulfur was achieved.

The composition of the sulfur binder applied as the industrial waste: $97.86 \% \mathrm{~S}_{8}$ fine sulfur, oil: $2.13 \%$, the ash: $0.01 \%$, producer "Siarkopol" Tarnobrzeg. The composition of the sulfur binder is presented in Table 1.

The results of the preliminary tests were analyzed, and the special polymerized sulfur in the industries objects having the best properties among the tested composites was selected for further studies. The information about the preparation of special polymerized sulfur is presented in Table 2. The composition of the special polymerized sulfur applied as the industrial waste is presented in Table 3, and its experimentally determined properties is shown in Table 4. The sulfur binder used for investigations, applied as the industrial waste, is shown in Fig. 3. Sulfur came from desulfurization of the fuel of diesel. 
Table 2 Preparation of special polymerized sulfur

\begin{tabular}{llll}
\hline Binder & Temperature of the polymerization $\left({ }^{\circ} \mathrm{C}\right)$ & $\begin{array}{l}\text { Time of the poly- } \\
\text { merization (min) }\end{array}$ & $\begin{array}{l}\text { Time of coagula- } \\
\text { tion (min) }\end{array}$ \\
\hline Sulfur applied as the industrial waste & $150-160$ & $20-40$ & $20-30$ \\
\hline
\end{tabular}

Table 3 Composition of the special sulfur composite

\begin{tabular}{lll}
\hline Content in $(\%)$ of total composite mass & \\
\hline Binder & Filler & Additive \\
\hline Sulfur $(\%)$ & Mineral quartz dust $(\%)$ & Technical soot $(\%)$ \\
98 & 0 & 2 \\
\hline
\end{tabular}

Table 4 Experimentally determined properties of special sulfur composite

\begin{tabular}{|c|c|c|c|c|c|c|c|}
\hline $\begin{array}{l}\text { Average } \\
\text { bulk density } \\
\rho_{p m}\left(\mathrm{~g} / \mathrm{cm}^{3}\right)\end{array}$ & $\begin{array}{l}\text { Average } \\
\text { absorbability } \\
\text { by wt. } n_{w m} \\
(\%)\end{array}$ & $\begin{array}{l}\text { Average } \\
\text { bending } \\
\text { strength } \\
f_{d m} \\
(\mathrm{MPa})\end{array}$ & $\begin{array}{l}\text { Average } \\
\text { splitting } \\
\text { tensile } \\
\text { strength } \\
f_{c t, s p} \\
(\mathrm{MPa}) \\
\end{array}$ & $\begin{array}{l}\text { Average } \\
\text { com- } \\
\text { pressive } \\
\text { strength } \\
f_{c m c} \\
(\mathrm{MPa}) \\
\end{array}$ & $\begin{array}{l}\text { Coefficient of } \\
\text { fragility } k(-)\end{array}$ & $\begin{array}{l}\text { Coefficient of } \\
\text { direct elas- } \\
\text { ticity } E_{d m} \\
\text { under bend- } \\
\text { ing }(\mathrm{GPa})\end{array}$ & $\begin{array}{l}\text { Coefficient of } \\
\text { direct elastic- } \\
\text { ity } E_{c m} \text { under } \\
\text { compression } \\
(\mathrm{GPa})\end{array}$ \\
\hline 1.98 & $0.01-0.02$ & $\frac{10.0}{5.8 \%}$ & $\frac{3.0}{7.2} \%$ & $\frac{40.0}{8.5 \%}$ & 0.90 & $55-60$ & $60-65$ \\
\hline
\end{tabular}

The percentages under the line are coefficients of variation

\subsubsection{Filler}

The filler used in this production was technical soot "Seva Carb" (granulation: 0.330-0.990 $\mu \mathrm{m}$ ). Technical soot with maximum grain size of $0.990 \mu \mathrm{m}$ was used as an filler. Chemical analysis indicated that the filler mainly consisted of carbon $(99.90 \%)$.

\subsubsection{Cement}

Ordinary portland cement CEM I 32,5 R was used in this study.

\subsection{Preparation and characterization of concrete samples}

Special sulfur composite was prepared according to the manufacturing technological procedure described in the literature [19-25].

The portland cement concrete mixtures were prepared according to the literature [19-25]. Portland cement and water-to-cement ratio $\mathrm{w} / \mathrm{c}$ of 0.70 , were mixed in automatic mixer.

The aggregate was first charged into the mixer and mixed with some tap water. Then, the cement and the rest of the mixing water were added and the homogenization continued. The overall mixing time was about 6 $\min$. The concrete mixture was poured into molds and compacted by a vibration table. The specimens were demolded $24 \mathrm{~h}$ after casting and then cured in a moist room at a temperature of $20 \pm 2{ }^{\circ} \mathrm{C}$ with $95-98 \%$ relative humidity for 27 additional days, before being subjected to the tests. The prism-shaped samples with dimensions $40 \times 40 \times 160(\mathrm{~mm})$, were prepared.

Each reported value is the average of three readings obtained from three different samples, to ensure the reliability of the test results.

Mechanical strength (compressive and flexural) of the concrete samples was conducted using the "Tecnotest" Modena-Italy press with maximum load of $2000 \mathrm{kN}$, and method for testing the strength of concrete according to the standard (Fig. 4).

The composition and relevant starting physico-mechanical properties of the prepared reference concrete samples were presented in the literature [19-36]. 

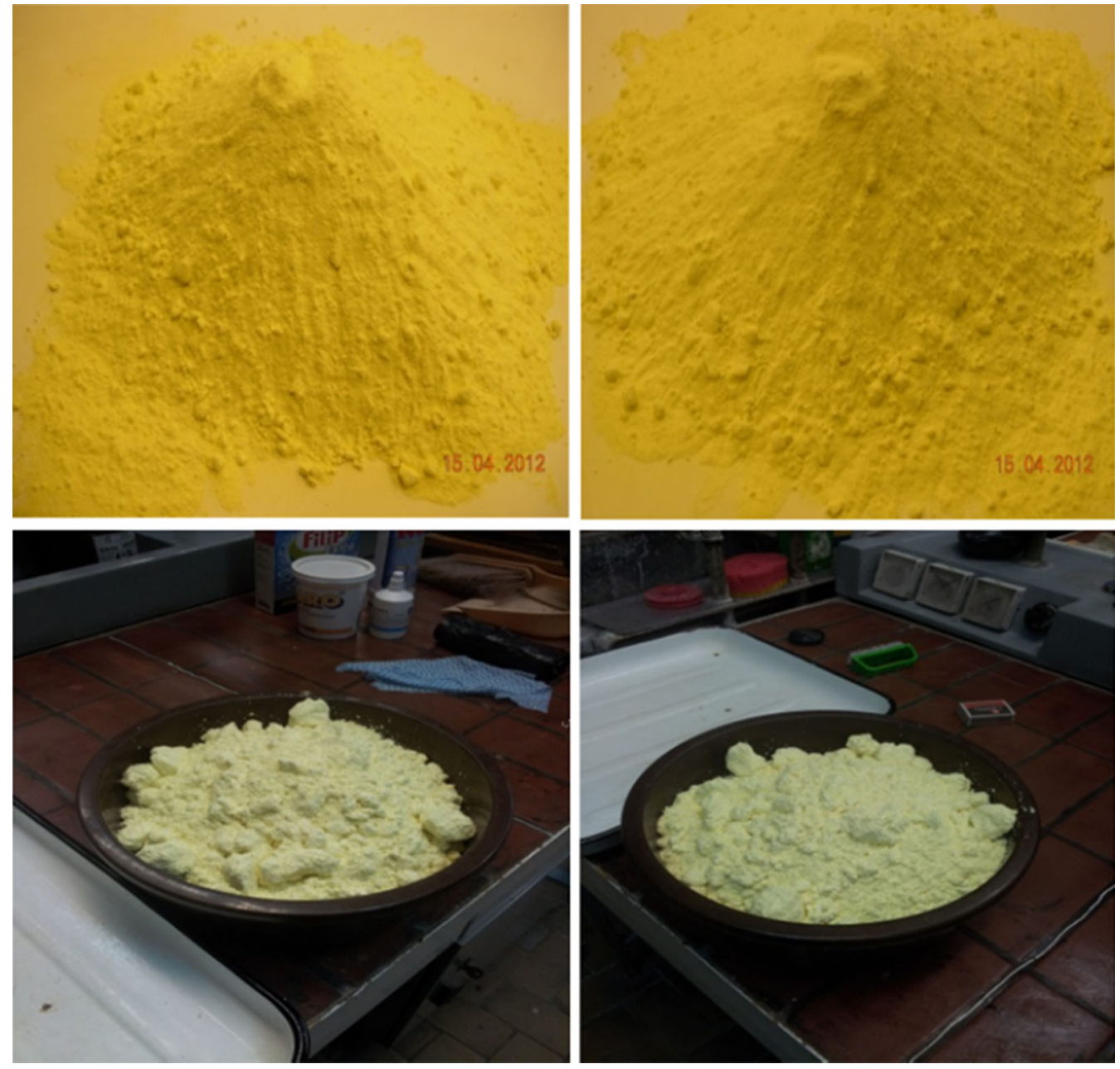

Fig. 3 View of the sulfur used to investigations
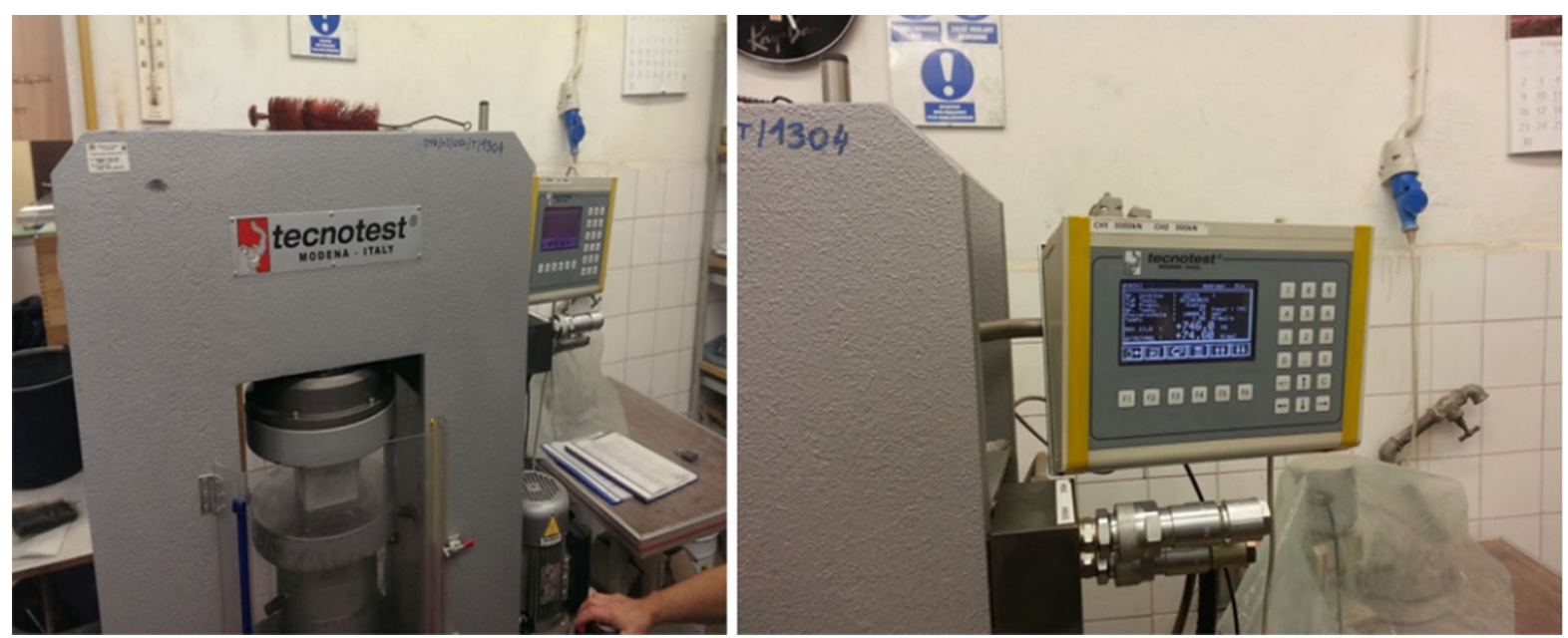

Fig. 4 View of the hydraulic press used to investigations 

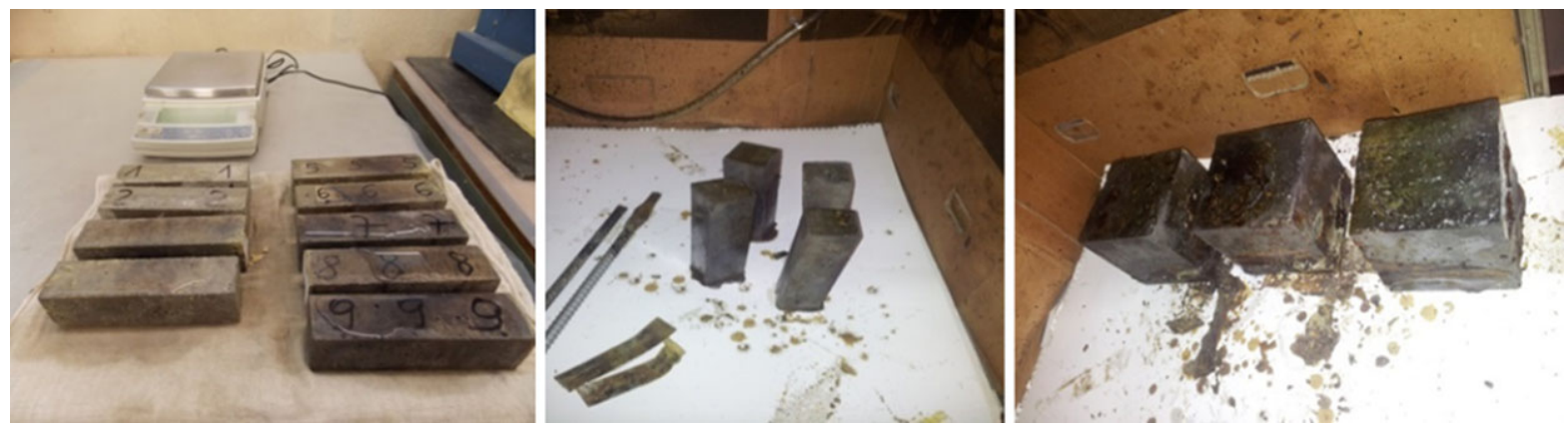

Fig. 5 View of the samples concrete and mortar impregnated with special sulfur composite

\subsection{Samples used to investigations}

Samples: $40 \times 40 \times 160(\mathrm{~mm})($ mortar$)$ and $100 \times 100 \times 100(\mathrm{~mm})($ concrete) rectangular samples were used to determine mechanical strength, mass and surface destruction level and water absorption by weight of the sulfur composite. The loss in weight of ordinary concrete impregnated with sulfur composite, kept in aqueous solutions of acids, hydroxides, salts and in water for a year was determined using $100 \times 100 \times 100(\mathrm{~mm})$ samples. The same samples were then used in compressive strength tests.

The samples concrete and mortar impregnated with special sulfur composite are shown in Fig. 5.

Special polymer sulfur composite applied as the industrial waste was investigated in two stages. In the first stage, compositions were fixed and thirty test special sulfur were prepared and pretested. The pretesting included preparing special polymerized sulfur and determining their basic physical, chemical properties and mechanical properties, such as thermoplastic properties, bulk density, absorbability by wt., bending strength and splitting tensile strength. Details were passed in the literature [16,19-36].

\section{Impregnation technique}

It was prepared by melting special polymerized sulfur (polymer coating) at the temperature $150-155{ }^{\circ} \mathrm{C}$ and then by cooling to the ambient temperature. The samples and elements were immersed for 5-10 min and remaining specimens for $0-5$ hours in molten special polymer sulfur coating. The specimens were then removed from the steel vessel, and excess liquid sulfur on the surface was wiped off. The samples and elements were cooled in water for $20 \mathrm{~min}$ in order to crystallize the sulfur in the surface pores and prevent loss of sulfur by evaporation and were then left at room temperature to cool in the air. The specimens were weighed before and after impregnation and sulfur loading calculated. The impregnated specimens look shiny greenish to dark gray depending upon the original color of the specimens (Fig. 2). However, the rough texture is not very much affected. The total process time is 00:20-00:30 hours (20-30 min.) for samples and elements. Details were passed in the literature Książek [19-36].

The samples concrete and cement mortar was impregnated with special polymerized sulfur (polymer coating) applied as the industrial waste view of Fig. 5.

The impregnation caused saturation of the pores of cement composites and the strain hardening of surface.

\section{Investigation results and analysis}

\subsection{Thermoplastic properties}

The thermoplastic properties of special polymerized sulfur were examined. Sulfuric binder used in investigations as the industrial waste is shown in Fig. 3. The thermoplastic properties of special polymerized sulfur as a function of temperature is shown in Fig. 6 [19-25].

Special polymerized sulfur possesses the lemon yellow sintered microcrystals. Chemical element of the special polymerized sulfur and the spectral lines of special polymerized sulfur, applied as the industrial waste is shown in Fig. 7 [19-30]. 

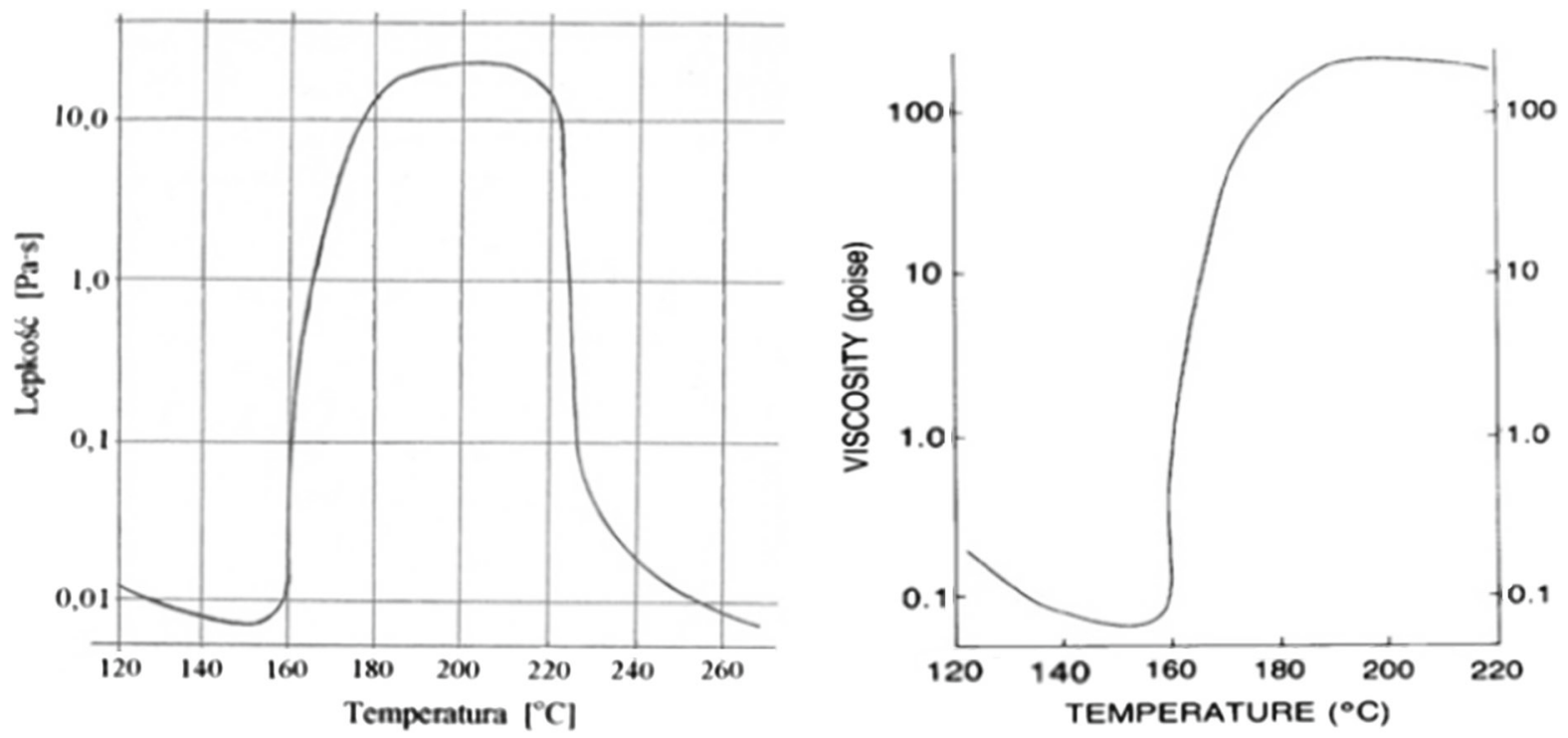

Fig. 6 View of the thermoplastic properties of special polymerized sulfur as a function of temperature [19-25]

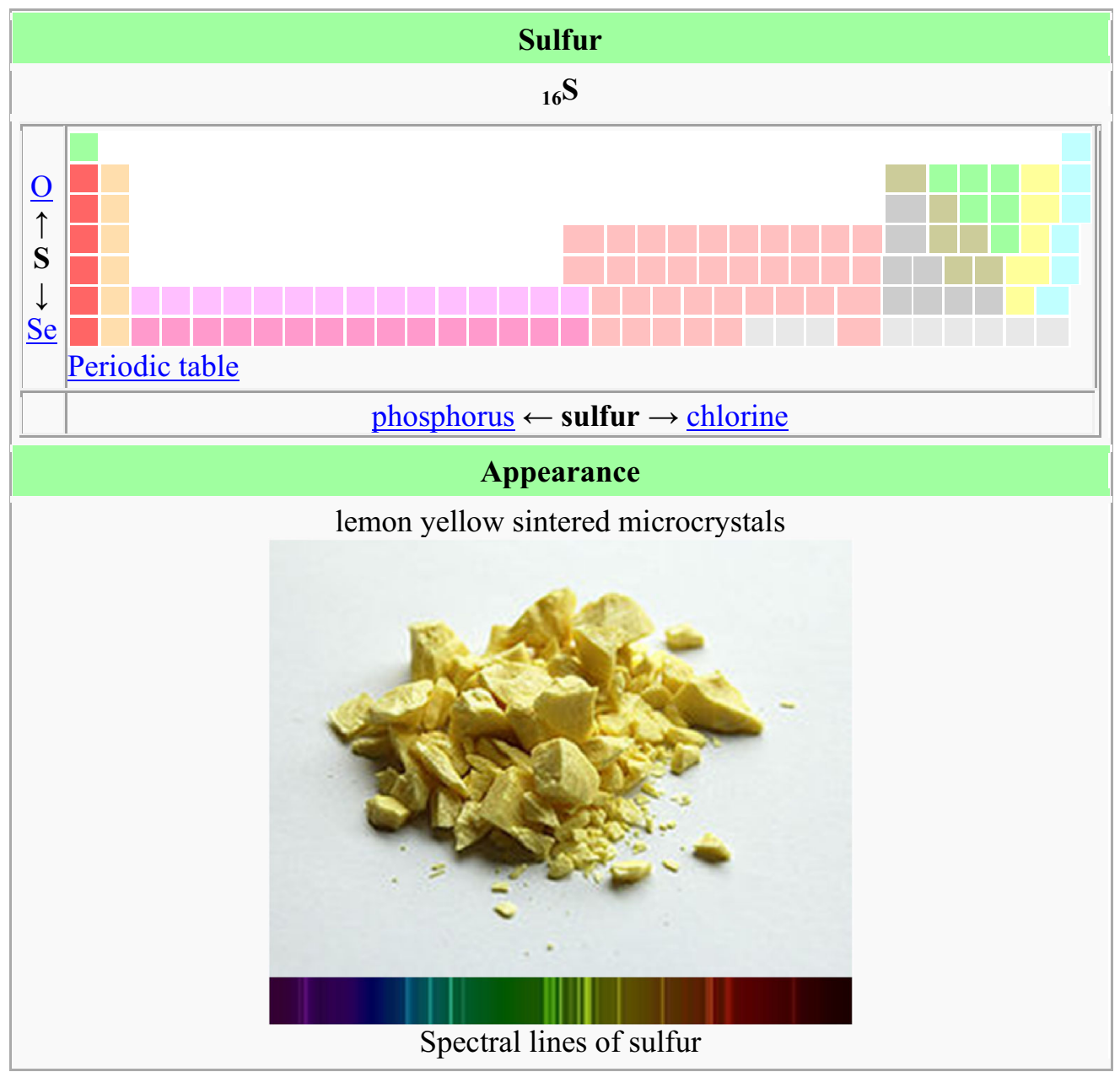

Fig. 7 View of the chemical element of special polymerized sulfur and the spectral lines of special polymerized sulfur [19-30] 
In 2008-2015, author reported on research with special polymerized sulfur (polymer coating)—infiltrated concrete and building mortar and noted that waste sulfur has economical advantages over organic polymer. When the impregnation was vacuum assisted, an exceedingly strong and durable concretes and building mortars could be produced by precasting. Author did not recommend his particular formulation for cast-in-place use. In effect, the waste sulfur was used as a substitute for some of the portland cement, because the concrete and building mortar, being infiltrated, had a water-cement (w/c) ratio of 0.70 , about 4.0 bag/yd. 3. In 2008-2015, it was concluded that at least in Poland this infiltrated concrete and building mortar would probably be less costly than portland cement concrete having a w/c of 0.40 . The sulfur infiltrated concrete had a compressive strength of over $0.000 \mathrm{lb} . / \mathrm{in} .2\left(700 \mathrm{~kg} / \mathrm{cm}^{2}\right)$, withstood 200 cycles of freezing and thawing without damage and was exceedingly resistant to chemical attack. Apparently, the special polymerized sulfur fills the capillaries and prevents absorption of water or chemicals, and this prevents the critical saturation that causes freeze-thaw distress. A personal communication from author indicated that there had been no change in the properties of this laboratory concrete in five years [4-8].

The impregnation caused saturation of the pores of cement composites and the strain hardening of surface.

\subsection{Deduction of correlation for particular cases}

Several particular cases of a special polymer sulfur composites with disoriented inclusions are considered. Consider uniformly disoriented inclusions and the mean constants $\left\langle\lambda_{i j}^{*}\right\rangle$ and $\left\langle\beta_{i j}^{*}\right\rangle$ corresponding to Voigt averaging are calculated. Setting $f(\theta, \varphi, \psi)=1.0$ in Eq. (9), it is evident that the problem reduces to averaging the sum of the products of the directional cosines [41].

After substituting Eq. (8) into Eq. (9) and taking into account Eq. (7), the result obtained is [41]:

$$
\begin{aligned}
& \left\langle\lambda_{11}^{*}\right\rangle=\left\langle\lambda_{22}^{*}\right\rangle=\left\langle\lambda_{33}^{*}\right\rangle=1 / 5\left(\lambda_{11}^{*}+\lambda_{22}^{*}+\lambda_{33}^{*}\right)+2 / 5\left(\lambda_{12}^{*}+\lambda_{13}^{*}+\lambda_{23}^{*}+2 \lambda_{44}^{*}+2 \lambda_{55}^{*}+2 \lambda_{66}^{*}\right) ; \\
& \left\langle\lambda_{12}^{*}\right\rangle=\left\langle\lambda_{13}^{*}\right\rangle=\left\langle\lambda_{23}^{*}\right\rangle=1 / 15\left(\lambda_{11}^{*}+\lambda_{22}^{*}+\lambda_{33}^{*}\right)+4 / 15\left(\lambda_{12}^{*}+\lambda_{13}^{*}+\lambda_{23}^{*}\right)-2 / 15\left(\lambda_{44}^{*}+\lambda_{55}^{*}+\lambda_{66}^{*}\right) ; \\
& \left\langle\lambda_{44}^{*}\right\rangle=\left\langle\lambda_{55}^{*}\right\rangle=\left\langle\lambda_{55}^{*}\right\rangle=1 / 2\left(\left\langle\lambda_{11}^{*}\right\rangle-\left\langle\lambda_{22}^{*}\right\rangle\right) ; \quad\left\langle\beta_{11}^{*}\right\rangle=\left\langle\beta_{22}^{*}\right\rangle=\left\langle\beta_{33}^{*}\right\rangle=1 / 3\left(\beta_{11}^{*}+\beta_{22}^{*}+\beta_{33}^{*}\right) .
\end{aligned}
$$

Thus, it is evident that the special polymer sulfur composites consist of an isotropic medium in a macrovolume. The mean elastic pliability matrix $\left\langle S_{i j}^{*}\right\rangle$ and the coefficients of linear thermal expansions $\left\langle\alpha_{m n}^{*}\right\rangle$, corresponding to Rice averaging, may be calculated analogously [41].

Consider the case in which the inclusions are uniformly and continuously distributed within the interval $0 \leq \theta<\theta^{*}, 0 \leq \varphi<2 \pi, 0 \leq \psi<2 \pi$, where $\theta^{*}$ is the maximum angle of fiber deviation from axes $x_{3}$. In this case, the distribution function $f(\theta, \varphi, \psi)$ will take the form [41]:

$$
f(\theta, \varphi, \psi)=a h_{\theta^{*}}(\theta) .
$$

Here $h_{\theta^{*}}(\theta)$ is the indicator function of the angle $\theta$ [41]:

$$
h_{\theta^{*}}(\theta)= \begin{cases}1 ; & 0 \leq \theta \leq \theta^{*} \\ 0 ; & \theta^{*} \leq \theta \leq \pi\end{cases}
$$

and $a$ is found from the normalization condition [41]:

$$
\frac{1}{8 \pi^{2}} \int_{0}^{\pi} \int_{0}^{2 \pi} \int_{0}^{2 \pi} f(\theta, \varphi, \psi) \sin \theta d \theta d \varphi d \psi=1 .
$$

Substitution of Eqs. (12), (13) into Eq. (14) gives [41]:

$$
a=\frac{2}{1-\cos \theta^{*}},
$$

and taking account of Eq. (12), it follows that [41]:

$$
f(\theta, \varphi, \psi)=\frac{2}{1-\cos \theta^{*}} h_{\theta^{*}}(\theta) .
$$


Now, knowing $f(\theta, \varphi, \psi)$, the mean constants $\left\langle\lambda_{i j}^{*}\right\rangle$ and $\left\langle\beta_{i j}^{*}\right\rangle$ may be found from Eqs. (7) to (9). Omitting intermediate calculations, the mean thermoplastic moduli are as follows [41]:

$$
\begin{aligned}
\left\langle\lambda_{11}^{*}\right\rangle= & \left\langle\lambda_{22}^{*}\right\rangle=3 a_{1}\left(\lambda_{11}^{*}+\lambda_{22}^{*}\right)+3 a_{2} \lambda_{33}^{*}+2 a_{3}\left(\lambda_{23}^{*}+\lambda_{13}^{*}+2 \lambda_{44}^{*}+2 \lambda_{55}^{*}\right)+2 a_{1}\left(\lambda_{12}^{*}+2 \lambda_{66}^{*}\right) ; \\
\left\langle\lambda_{33}^{*}\right\rangle= & 3 a_{2}\left(\lambda_{11}^{*}+\lambda_{22}^{*}\right)+a_{4} \lambda_{33}^{*}+2 a_{5}\left(\lambda_{23}^{*}+\lambda_{13}^{*}+2 \lambda_{44}^{*}+2 \lambda_{55}^{*}\right)+2 a_{2}\left(\lambda_{12}^{*}+2 \lambda_{66}^{*}\right) ; \\
\left\langle\lambda_{23}^{*}\right\rangle= & \left\langle\lambda_{13}^{*}\right\rangle=a_{3}\left(\lambda_{11}^{*}+\lambda_{22}^{*}\right)+a_{5} \lambda_{33}^{*}+2\left(a_{6}+a_{2}\right)\left(\lambda_{13}^{*}+\lambda_{23}^{*}\right) \\
& +2\left(a_{3}+a_{5}\right) \lambda_{12}^{*}-2 a_{2}\left(\lambda_{44}^{*}+\lambda_{55}^{*}\right)-2 a_{7} \lambda_{66}^{*} ; \\
\left\langle\lambda_{44}^{*}\right\rangle= & \left\langle\lambda_{55}^{*}\right\rangle=a_{3}\left(\lambda_{11}^{*}+\lambda_{22}^{*}\right)+a_{5} \lambda_{33}^{*}-a_{5}\left(\lambda_{13}^{*}+\lambda_{23}^{*}\right)-a_{2} \lambda_{12}^{*}+ \\
& +\left(2 a_{6}+2 a_{2}-a_{5}\right)\left(\lambda_{44}^{*}+\lambda_{55}^{*}\right)+\left(2 a_{3}+a_{2}\right) \lambda_{66}^{*} ; \\
\left\langle\lambda_{66}^{*}\right\rangle= & 1 / 2\left(\left\langle\lambda_{11}^{*}\right\rangle-\left\langle\lambda_{22}^{*}\right\rangle\right) ; \\
\left\langle\beta_{11}^{*}\right\rangle= & \left\langle\beta_{22}^{*}\right\rangle=a_{8}\left(\beta_{11}^{*}+\beta_{22}^{*}\right)+a_{9} \beta_{33}^{*} ;\left\langle\beta_{33}^{*}\right\rangle=a_{9}\left(\beta_{11}^{*}+\beta_{22}^{*}\right)+a_{10} \beta_{33}^{*} .
\end{aligned}
$$

Here $a_{i}(i=1, \ldots, 10)$ takes the form [41]:

$$
\begin{aligned}
a_{1} & =1 / 960\left(64+19 \cos \theta^{*}+19 \cos ^{2} \theta^{*}+9 \cos ^{3} \theta^{*}+9 \cos ^{4} \theta^{*}\right) ; \\
a_{2} & =1 / 120\left(8-7 \cos \theta^{*}-7 \cos ^{2} \theta^{*}+3 \cos ^{3} \theta^{*}+3 \cos ^{4} \theta^{*}\right) ; \\
a_{3} & =1 / 240\left(16+\cos \theta^{*}+\cos ^{2} \theta^{*}-9 \cos ^{3} \theta^{*}-9 \cos ^{4} \theta^{*}\right) ; \\
a_{4} & =1 / 5\left(1+\cos \theta^{*}+\cos ^{2} \theta^{*}+\cos ^{3} \theta^{*}+\cos ^{4} \theta^{*}\right) ; \\
a_{5} & =1 / 30\left(2+2 \cos \theta^{*}+2 \cos ^{2} \theta^{*}-3 \cos ^{3} \theta^{*}-3 \cos ^{4} \theta^{*}\right) ; \\
a_{6} & =1 / 120\left(8+8 \cos \theta^{*}+8 \cos ^{2} \theta^{*}+3 \cos ^{3} \theta^{*}+3 \cos ^{4} \theta^{*}\right) ; \\
a_{7} & =1 / 480\left(32+47 \cos \theta^{*}+47 \cos ^{2} \theta^{*}-3 \cos ^{3} \theta^{*}-3 \cos ^{4} \theta^{*}\right) ; \\
a_{8} & =1 / 12\left(4+\cos \theta^{*}+\cos ^{2} \theta^{*}\right) ; \quad a_{9}=1 / 6\left(2-\cos \theta^{*}-\cos ^{2} \theta^{*}\right) . \\
a_{10} & =1 / 3\left(1+\cos \theta^{*}+\cos ^{2} \theta^{*}\right) ; \quad[41] .
\end{aligned}
$$

Thus, it is evident from the relations obtained that such a special polymer sulfur composites are transversely isotropic. Note that, when $\theta^{*}=\pi / 2$, the case in which the inclusions are uniformly disoriented is obtained [41].

In fact [41]:

$$
a_{1}=a_{2}=a_{3}=a_{5}=a_{6}=a_{7}=1 / 15 ; \quad a_{4}=1 / 5 ; \quad a_{8}=a_{9}=a_{10}=1 / 3,
$$

and Eq. (17) reduces to Eq. (11) [41].

Setting $\theta^{*}=0$ in Eq. (18) yields the case in which the ellipsoidal inclusions are uniformly disoriented in the plane $x_{1}^{\prime} x_{2}^{\prime}$, but still oriented along the axis $x_{3}^{\prime}$. In this case [41]:

$$
a_{1}=1 / 8 ; \quad a_{2}=a_{3}=a_{5}=a_{9}=0 ; \quad a_{4}=a_{10}=1 ; \quad a_{6}=a_{7}=1 / 4 ; \quad a_{8}=1 / 2 .
$$

Then, taking account of Eq. (20), Eq. (17) may be written in the form [41]:

$$
\begin{aligned}
& \left.\left\langle\lambda_{11}^{*}\right\rangle=\left\langle\lambda_{22}^{*}\right\rangle=3 / 8\left(\lambda_{11}^{*}+\lambda_{22}^{*}\right)+1 / 4 \lambda_{12}^{*}+1 / 2 \lambda_{66}^{*}\right) ; \quad\left\langle\lambda_{33}^{*}\right\rangle=\lambda_{33}^{*} ; \\
& \left.\left\langle\lambda_{13}^{*}\right\rangle=\left\langle\lambda_{23}^{*}\right\rangle=1 / 2\left(\lambda_{13}^{*}+\lambda_{23}^{*}\right) ; \quad\left\langle\lambda_{12}^{*}\right\rangle=1 / 8\left(\lambda_{11}^{*}+\lambda_{22}^{*}\right)+3 / 4 \lambda_{12}^{*}-1 / 2 \lambda_{66}^{*}\right) ; \\
& \left\langle\lambda_{44}^{*}\right\rangle=\left\langle\lambda_{55}^{*}\right\rangle=1 / 2\left(\lambda_{44}^{*}+\lambda_{55}^{*}\right) ; \quad\left\langle\lambda_{66}^{*}\right\rangle=1 / 2\left(\left\langle\lambda_{11}^{*}\right\rangle-\left\langle\lambda_{22}^{*}\right\rangle\right) ; \\
& \left\langle\beta_{11}^{*}\right\rangle=\left\langle\beta_{22}^{*}\right\rangle=1 / 2\left(\beta_{11}^{*}+\beta_{22}^{*}\right) ; \quad\left\langle\beta_{33}^{*}\right\rangle=\beta_{33}^{*} . \quad[41] .
\end{aligned}
$$

Note also that, these formulas may be obtained directly from Eq. (9), taking into account that the distribution function for inclusions, disoriented in the plane $x_{1}^{\prime} x_{2}^{\prime}$, takes the form [41]:

$$
f(\theta, \varphi, \psi)=4 \pi \delta(\theta) \delta(\psi) / \sin (\theta) .
$$

Now consider the case in which inclusions are uniformly and continuously distributed in the interval $0 \leq \theta<$ $\theta^{*}, 0 \leq \varphi<2 \pi$, and $\psi=0$. In this case, $f(\theta, \varphi, \psi)$ takes the form [41]:

$$
f(\theta, \varphi, \psi)=b h_{\theta^{*}}(\theta) \delta(\psi) .
$$


Here, $h_{\theta^{*}}(\theta)$ is the indicator function of the angle $\theta$ in Eq. (13), and $b$ is found from the normalization condition Eq. (14) [41]:

$$
b=\frac{4 \pi}{1-\cos \theta^{*}} .
$$

Then, taking account of Eqs. (23), (24) may be written in the form [41]:

$$
f(\theta, \varphi, \psi)=\frac{4 \pi}{1-\cos \theta^{*}} h_{\theta^{*}}(\theta) \delta(\psi) .
$$

Without going through the details of the calculations, the mean elastic moduli in this case may be written in the form [41]:

$$
\begin{aligned}
& \left\langle\lambda_{11}^{*}\right\rangle=\left\langle\lambda_{22}^{*}\right\rangle=3 a_{1} \lambda_{11}^{*}+3 a_{2} \lambda_{22}^{*}+3 a_{4} \lambda_{33}^{*}+6 a_{5}\left(\lambda_{23}^{*}+2 \lambda_{44}^{*}\right)+2 a_{3}\left(\lambda_{13}^{*}+2 \lambda_{55}^{*}\right)+2 a_{1}\left(\lambda_{12}^{*}+2 \lambda_{66}^{*}\right) ; \\
& \left\langle\lambda_{33}^{*}\right\rangle=8 a_{4} \lambda_{22}^{*}+8 a_{2} \lambda_{33}^{*}+16 a_{5}\left(\lambda_{23}^{*}+2 \lambda_{44}^{*}\right) ;\left\langle\lambda_{66}^{*}\right\rangle=1 / 2\left(\left\langle\lambda_{11}^{*}\right\rangle-\left\langle\lambda_{22}^{*}\right\rangle\right) ; \\
& \left\langle\lambda_{23}^{*}\right\rangle=\left\langle\lambda_{13}^{*}\right\rangle=4 a_{5}\left(\lambda_{22}^{*}+\lambda_{33}^{*}\right)+4\left(a_{2}+a_{4}\right) \lambda_{23}^{*}+4 a_{1} \lambda_{13}^{*}+4 a_{3} \lambda_{12}^{*}-4 a_{5} \lambda_{44}^{*} ; \\
& \left\langle\lambda_{12}^{*}\right\rangle=a_{1} \lambda_{11}^{*}+a_{2} \lambda_{22}^{*}+a_{4} \lambda_{33}^{*}+2 a_{5} \lambda_{23}^{*}+6 a_{3} \lambda_{13}^{*}+6 a_{1} \lambda_{12}^{*}+4 a_{5} \lambda_{44}^{*}-4 a_{3} \lambda_{55}^{*}-4 a_{1} \lambda_{66}^{*} ; \\
& \left.\left\langle\lambda_{44}^{*}\right\rangle=\left\langle\lambda_{55}^{*}\right\rangle=4 a_{5}\left(\lambda_{221}^{*}+\lambda_{33}^{*}-2 \lambda_{23}^{*}\right)+4\left(a_{2}+a_{4}-2 a_{5}\right) \lambda_{44}^{*}+4 a_{1} \lambda_{55}^{*}+4 a_{3} \lambda_{66}^{*}\right) ; \\
& \left\langle\beta_{11}^{*}\right\rangle=\left\langle\beta_{22}^{*}\right\rangle=a_{6}\left(\beta_{11}^{*}+\beta_{22}^{*}\right)+a_{7} \beta_{33}^{*} ;\left\langle\beta_{33}^{*}\right\rangle=a_{7}\left(\beta_{11}^{*}+\beta_{22}^{*}\right)+a_{8} \beta_{33}^{*} .
\end{aligned}
$$

Here:

$$
\begin{aligned}
& a_{1}=1 / 24\left(1+\cos \theta^{*}+\cos ^{2} \theta^{*}\right) ; \quad a_{3}=1 / 24\left(2-\cos \theta^{*}-\cos ^{2} \theta^{*}\right) ; \\
& a_{2}=1 / 40\left(1+\cos \theta^{*}+\cos ^{2} \theta^{*}+\cos ^{3} \theta^{*}+\cos ^{4} \theta^{*}\right) ; \\
& a_{4}=1 / 120\left(8-7 \cos \theta^{*}-7 \cos ^{2} \theta^{*}+3 \cos ^{3} \theta^{*}+3 \cos ^{4} \theta^{*}\right) ; \\
& a_{5}=1 / 120\left(2+2 \cos \theta^{*}+2 \cos ^{2} \theta^{*}-3 \cos ^{3} \theta^{*}-3 \cos ^{4} \theta^{*}\right) ; \\
& a_{6}=1 / 2 ; \quad a_{7}=1 / 6\left(2-\cos \theta^{*}-\cos ^{2} \theta^{*}\right) ; \quad a_{8}=1 / 3\left(1+\cos \theta^{*}+\cos ^{2} \theta^{*}\right) . \quad \text { [41]. }
\end{aligned}
$$

Setting $\theta^{*}=0$ in Eq. (18) yields the case in which the ellipsoidal inclusions are uniformly disoriented in the plane $x_{1}^{\prime} x_{2}^{\prime}$, but oriented along the axis $x_{3}^{\prime}$. In this case [41]:

$$
a_{1}=a_{2}=1 / 8 ; \quad a_{3}=a_{4}=a_{5}=a_{7}=0 ; \quad a_{6}=1 / 2 ; \quad a_{8}=1 / 3 .
$$

Then, taking account of Eqs. (28), (26) reduces to Eq. (21).

Note also that the mean plastic-pliability matrix $\left\langle S_{i j}^{*}\right\rangle$ and the coefficients of linear thermal expansions $\left\langle\alpha_{m n}^{*}\right\rangle$ corresponding to Rice averaging may be calculated analogously [41].

\subsection{Numerical investigations: results and analysis}

As a numerical example, consider an arbolite based on straw particles and pores in special polymer sulfur composites with the plastic constants, respectively [41]:

$$
\begin{aligned}
E_{1}^{(1)} & =0.5 \cdot 10^{-9} P a ; \quad E_{2}^{(1)}=0.3 \cdot 10^{-9} P a ; E_{3}^{(1)}=6 \cdot 10^{-9} P a ; \\
G_{23}^{(1)} & =0.3 \cdot 10^{-9} P a ; G_{13}^{(1)}=0.36 \cdot 10^{-9} P a ; \\
G_{12}^{(1)} & =0.09 \cdot 10^{-9} P a ; v_{23}^{(1)}=0.025 ; \\
v_{13}^{(1)} & =0.3 ; v_{12}^{(1)}=0.6 ; E^{(2)}=30 \cdot 10^{-9} P a ; v^{(2)}=0.2 ; k_{2}=0.1 ; k_{3}=10 ; c_{0}=0.1 . \quad \text { [41]. }
\end{aligned}
$$

Here $k_{2}$ and $k_{3}$-the ratio of the semi-axes of ellipsoids (these parameters characterize the dimension of inclusions) and $c_{0}$-concentration of the pores in special polymer sulfur composites [41].

The results in Fig. 8 are calculated by the Voigt scheme. The dependencies of Young's modulus $\left\langle E_{3}^{*}\right\rangle$, Poisson's ratio $\left\langle v_{12}^{*}\right\rangle$, and shear modulus $\left\langle G_{12}^{*}\right\rangle$ from concentration of inclusions $c_{1}$ and for certain values of $k_{2}, k_{3}$ are shown in Fig. 9. The continuous curves correspond to uniform disorientation of the inclusions (UD) and disorientation of ellipsoids in the plane $x_{1}^{\prime} x_{2}^{\prime}$ (DP), and the dashed curves correspond to the case when the 

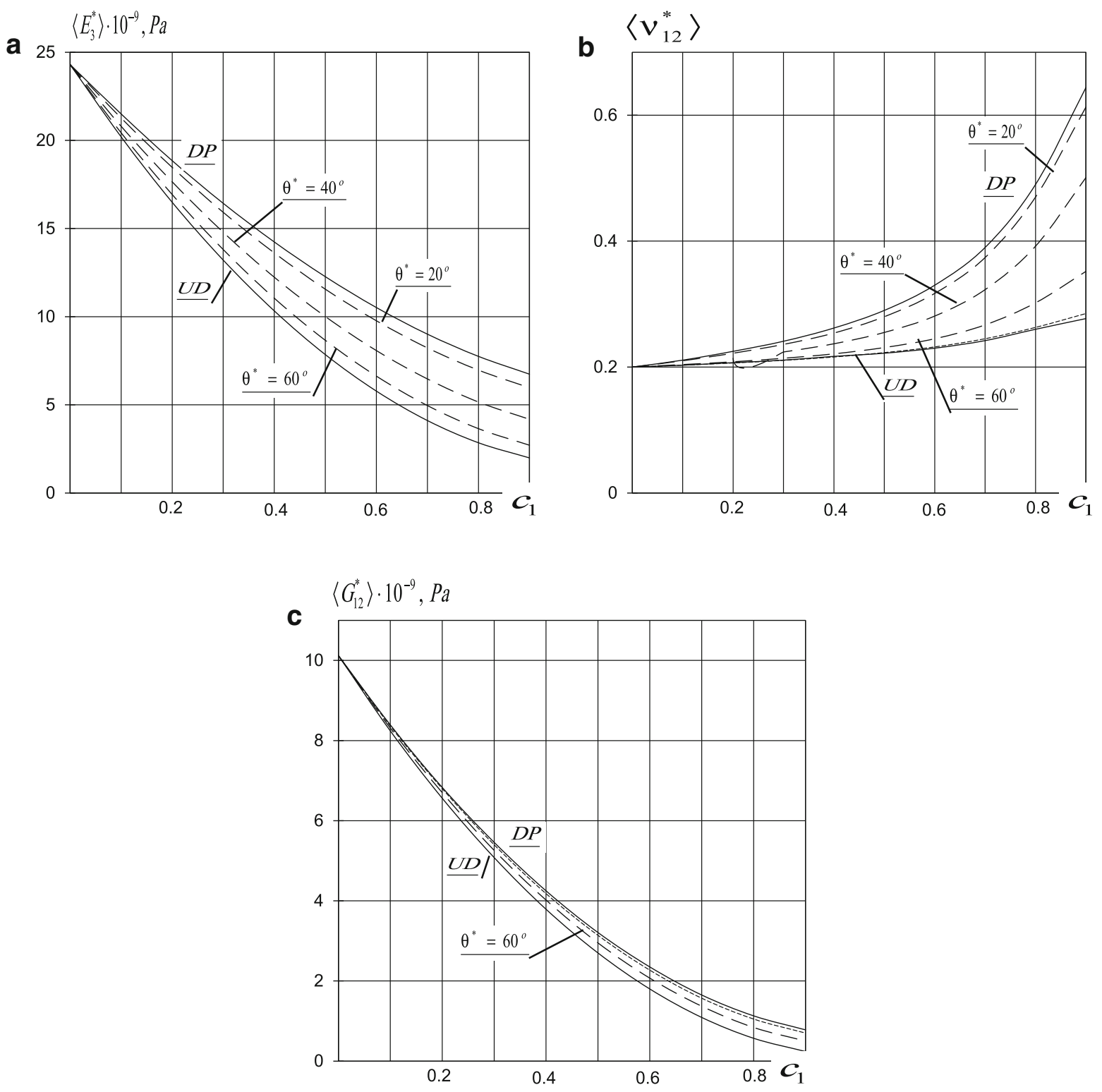

Fig. 8 A view the dependencies of Young's modulus $\left\langle E_{3}^{*}\right\rangle$, Poisson's ratio $\left\langle v_{12}^{*}\right\rangle$, and shear modulus $\left\langle G_{12}^{*}\right\rangle$ from concentration of inclusions $c_{1}$ and for certain values of $k_{2}, k_{3}$ are calculated by the Voigt scheme [41]

inclusions are uniformly and continuously distributed within the interval $0 \leq \theta<\theta^{*}, 0 \leq \varphi<2 \pi, 0 \leq \psi<$ $2 \pi$, where $\theta^{*}=20^{\circ}, 40^{\circ}, 60^{\circ}, 80^{\circ}[41]$.

Analogous results given by the Rice scheme are shown in Fig. 9. It is evident from the graphs that the numerical values of the macroscopic constants $\left\langle E_{3}^{*}\right\rangle,\left\langle G_{12}^{*}\right\rangle$ given by Voigt averaging are higher than those given by Rice averaging for all concentrations of the reinforcing inclusions [41].

The dependence of the constant $\left\langle v_{12}^{*}\right\rangle$ is more complicated in character. Note also that, the greatest discrepancy corresponds to concentrations of inclusions in the range 0.3-0.7. In some cases of considerable discrepancy between the Voigt and Rice results, the Hill approximation may be used, i.e., the arithmetic mean of the Voigt and Rice values [41].

Research was also successful in developing processes for partial depth impregnation that could be used in the field for impregnating bridge decks and other cement composites surface. The process required drying the concrete to remove moisture from the surface, applying the special polymer sulfur composites on a thin sand layer that held the special polymerized sulfur during the time the monomer was being imbibed into the concrete, 


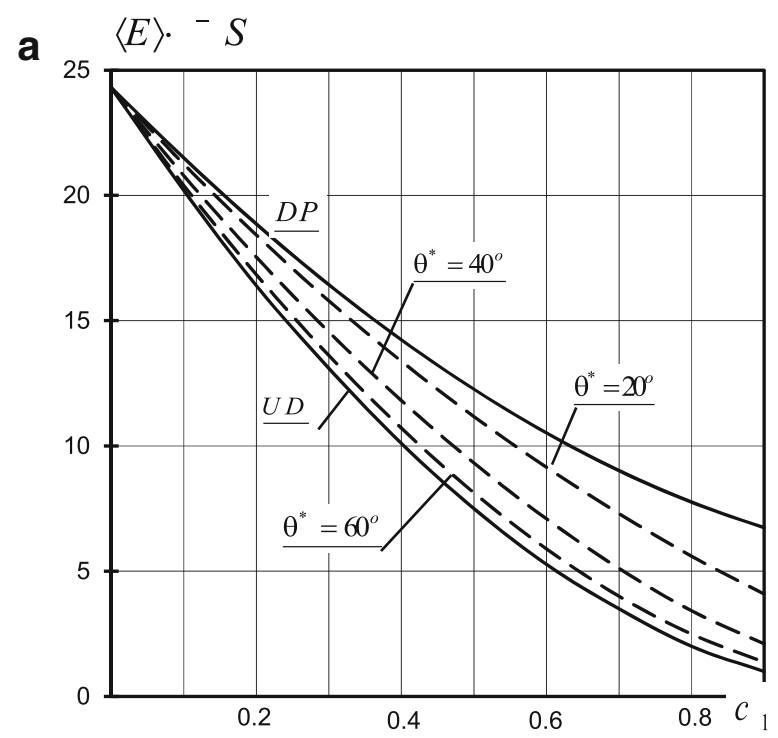

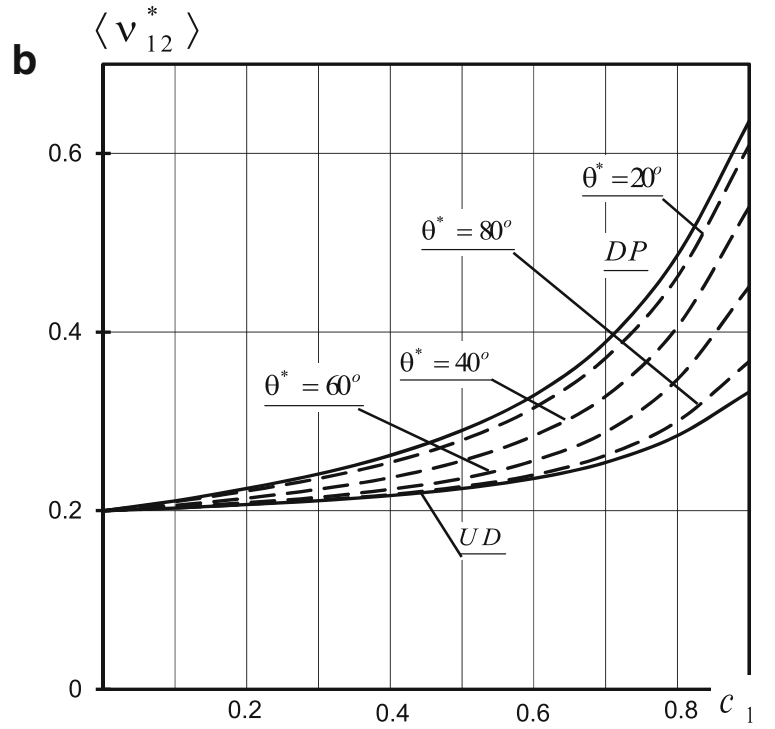

Fig.5

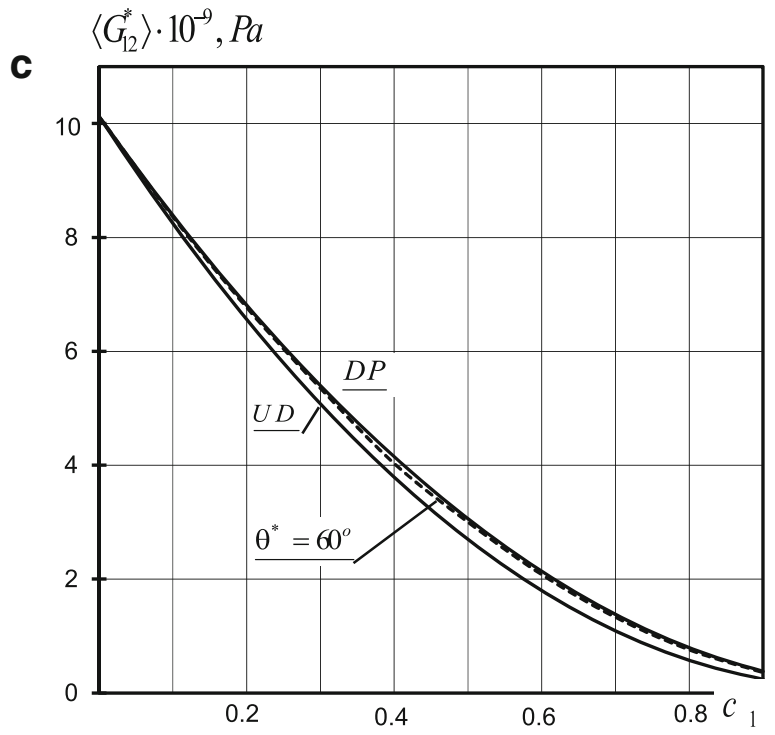

Fig.6

Fig. 9 A view the dependencies of Young's modulus $\left\langle E_{3}^{*}\right\rangle$, Poisson's ratio $\left\langle v_{12}^{*}\right\rangle$, and shear modulus $\left\langle G_{12}^{*}\right\rangle$ from concentration of inclusions $c_{1}$ and for certain values of $k_{2}, k_{3}$ are calculated by the Rice scheme [41]

and then polymerizing the monomer using steam heat. The process was capable of producing impregnated depths of 10-50 mm. The concrete surfaces were much more resistant to water absorption, had much higher abrasion resistant, and in generally were much more durable. The downside was that the process normally took about one day and subjected the concrete to high temperatures (thermal process) during drying that resulted in microcracking, and was rather cumbersome. Many bridge decks in the Poland were successfully impregnated during the 1980-1985, but the development of polymer concrete overlays provided a simpler, faster and less costly method for impregnated concrete surfaces [4-8,16,19-25].

More recently, however, there has been a successful commercial application of partial depth impregnation. The special polymer sulfur composites vacuum impregnation system uses a thermoplastic membrane that is applied over the surface of a slab, statue, column or wall and vacuum to evacuate the air from the pores. 


\section{Summary and conclusion}

The process of special polymer sulfur composites applied as the industrial waste production is a thermal treatment process in the temperature of about $150-155^{\circ} \mathrm{C}$. The result of such treatment is special polymer sulfur composites in a liquid state (thermoplastic properties).

This paper presents methods and results for determining the effective thermoplastic constants of special polymer sulfur composites with isotropic porous matrix reinforced by disoriented ellipsoidal orthotropic inclusions. The method is based on the use of conditional statistical averaging procedure and permits determining effective properties of essentially inhomogeneous special polymer sulfur composites possessing geometrical and physical anisotropy. The solution is constructed in two stages. First, the problem of the effective properties of special polymer sulfur composites with randomly distributed and oriented inclusions is solved. Then the problem of the effective properties of this composites is solved on the basis Voigt or Rice scheme. The effect of shape and concentration of inclusions, concentration of pores in matrix and the type of inclusion orientation has been studied [41].

The presented state of the art in the area of the PIC (special polymer sulfur composites-impregnated cement composites) shows the material complexity of the subject and the gap between polymer concretes and portland cement concretes regarding standardization, formal guidelines for production and recommendation for use. This determines the needs for the further works [4-8].

The result of such treatment is special polymer sulfur composites (polymer coatings) in a liquid state. Special polymer sulfur composites (polymer coatings) a liquid state are mixed with previously heated extender (thermal and plastics processes).

Recent research has led to the development of durable special polymer sulfur composites building mortars, concretes and coatings. All of the methods of using special polymer sulfur composites as a binder for rigid concrete rely on the reaction of one or more modifiers to stabilize, in the hardened state, at least a portion of the special polymer sulfur composites in its less brittle, less dense form. The durability of the concrete produced appears to depend on the modifying system used. In all cases, the special polymer sulfur composites must be heated to a liquid state to react with the modifier and to mix with and coat the aggregate and filler.

Special polymer sulfur composites (polymer coatings)-impregnated cement composites can develop high strength, attain strength in a $0-5$ hours, require no special curing, resist acids and organic liquids, has no known undesirable reactions with aggregates, and requires no limitation on the ambient temperature at the time of placement. When its use becomes economically feasible, concrete impregnated special polymer sulfur composites (polymer coatings) will be an excellent material for use in pavement repairs and bridge deck overlays.

Solidified impregnant in the small pores of solids is normally in metastable equilibrium. Spatial restrictions prohibit the formation of regular crystal habit. Because of the formation of noncrystalline modifications, the free energy is increased. In addition, owing to the large surface-to-volume ratio, the surface-free energy is also large. In the absence of concave menisci or strong interaction with the matrix that would reduce the energy, the tendency for spontaneous exudation from the pores is increased.

Special polymer sulfur composites (polymer coatings) do not interact strongly with siliceous surfaces, so that water or other liquids can penetrate the porous network and adsorb on the substrate surface, weakening further the interaction between it and sulfur. Water adsorbs also on sulfur, creating a lubricating effect and high stresses due to surface energy decrease. Both effects facilitate extrusion, and the latter causes destruction.

Because of the relatively slow penetration of water, non-isotropic expansion creates strains beyond the plastic limits.

Impregnated porous solids of small size can be successfully utilized for predicting the behavior of large sized systems.

Cement composites impregnated with special polymer sulfur composites (polymer coatings) are widely and successfully used in the repairs of the reinforced concrete structures as well as in their surface protection. Polymer mortars and mortars impregnated with special polymer sulfur composites (coatings) are used for making industrial floors. The main advantages are here excellent adhesion to the various materials, tightness and frost resistance, and in the case of the resin concretes also short time to exploitation readiness as discussed elsewhere [4-8].

The limitation can be relatively high setting shrinkage, as well as some differences between the properties of the repaired concrete and repair material-particularly high thermal expansion, creep, sometimes limited thermal resistance and ageing resistance. 


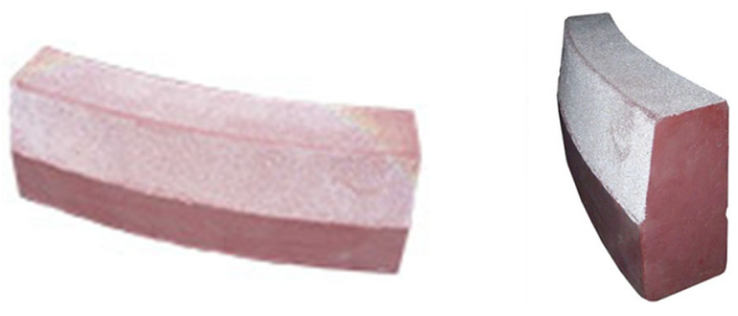

Fig. 10 View of concrete kerbs (edges) impregnated with special sulfur composite

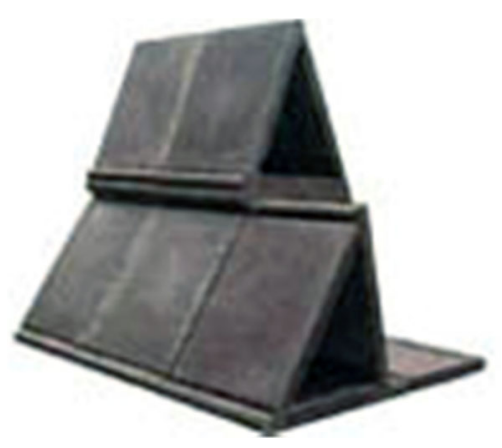

Fig. 11 View of marine structures impregnated with special sulfur composite
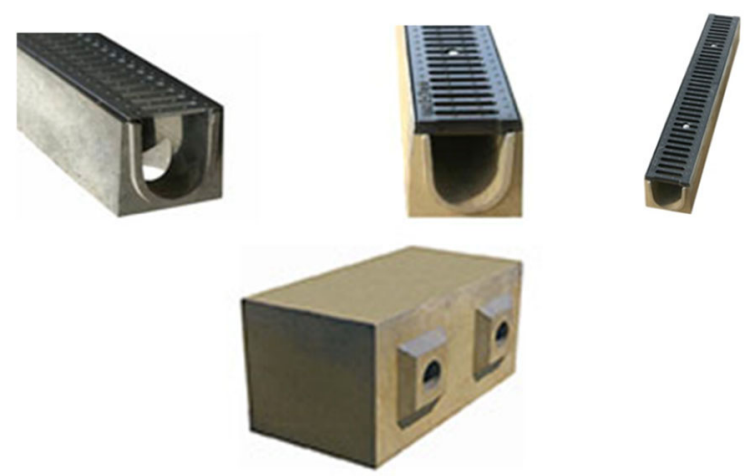

Fig. 12 View of line drainage system impregnated with special sulfur composite
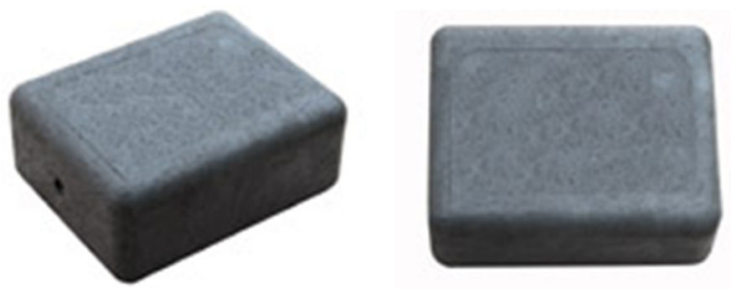

Fig. 13 View of lift counterweights impregnated with special sulfur composite

\section{Practical uses in building}

Practical uses of portland cement composites, impregnated with special polymer sulfur composites, in the building are shown in Figs. 10, 11, 12, 13 and 14. 


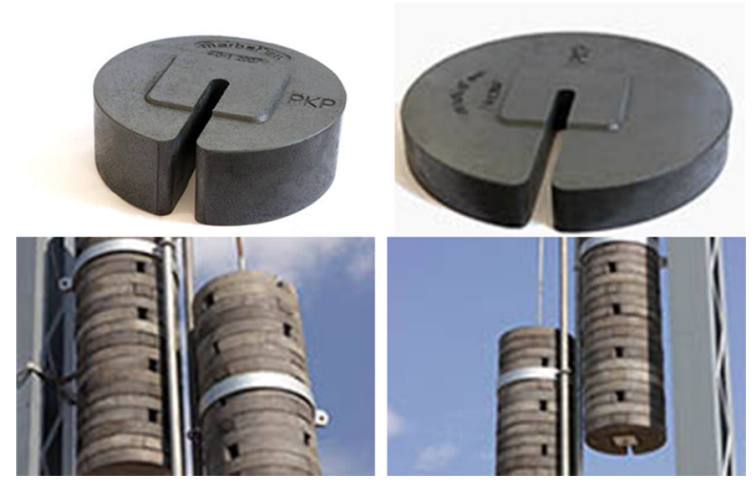

Fig. 14 View of railway weights impregnated with special sulfur composite

\section{Compliance with ethical standards}

Funding This study was not funded by any grant.

Conflict of interest The author declares and assures that no conflict exists.

Open Access This article is distributed under the terms of the Creative Commons Attribution 4.0 International License (http:// creativecommons.org/licenses/by/4.0/), which permits unrestricted use, distribution, and reproduction in any medium, provided you give appropriate credit to the original author(s) and the source, provide a link to the Creative Commons license, and indicate if changes were made.

\section{References}

1. Bień, J., Hoła, J., Sadowski, Ł.: Modern NDT techniques in diagnostics of transport infrastructure concrete structures. J. Nondestruct. Test. Ultrason. 18(11), 1-10 (2013). http://www.ndt.net/search/link.php?id=14888\&file=article/ndt-canada2013/ content/papers/36_Sadowski_Rev1.pdf

2. Błaszczyński, T.Z.: The influence of crude oil products on RC structure destruction. Civ. Eng. Manag. 17(1), 146-156 (2011). doi:10.3846/13923730.2011.561522

3. Criado, M., et al.: Corrosion behaviour of coated steel rebars in carbonated and chloride-contaminated alkali-activated fly ash mortar. Prog. Org. Coat. 99, 11-22 (2016). doi:10.1016/j.porgcoat.2016.04.040

4. Czarnecki, L., Garbacz, A.: Evaluation of polymer coating-crack-bridging ability. International Colloquium "Industrial Floors"95, Esslingen (1995)

5. Czarnecki, L., Emmons, P.H.: Repair and protection of concrete structures [Naprawa i Ochrona Konstrukcji Betonowych]. Wydawnictwo Polski Cement, Kraków (2002) (in Polish)

6. Czarnecki, L.: Polymer concretes. Cement Wapno Beton XV/LXXVII(2), 63-85 (2010)

7. Czarnecki, L., Głodkowska, W., Wiackowska, A.: Model of compatibility of polymer composite—cement concrete (PC-CC) System. In: Cardon, A. H., Verchery, G. (eds.) Durability of Polymer Based Composite Systems for Structural Applications, pp. 484-493. Elsevier (1991)

8. Czarnecki, L., Woyciechowski, P.: Concrete carbonation as a limited process and its relevance to concrete cover thickness. ACI Mater. J. Am. Concr. Inst. 109(3), 275 (2012)

9. Fiertak, M.: Trwałość materiałów budowlanych poddanych działaniom środowiska chemicznego (2005)

10. Głodkowska, W., Kobaka, J.: Modelling of properties and distribution of steel fibres within a fine aggregate concrete. Constr. Build. Mater. 44, 645-653 (2013)

11. Gorzelańczyk, T., Hoła, J., Sadowski, Ł., Schabowicz, K.: Methodology of nondestructive identification of defective concrete zones in unilaterally accessible massive members. Civ. Eng. Manag. 19(6), 775-786 (2013). doi:10.3846/13923730.2013. 812577

12. Hoła, J., Bień, J., Sadowski, Ł., Schabowicz, K.: Non-destructive and semi-destructive diagnostics of concrete structures in assessment of their durability. Bull. Pol. Acad. Sci. Tech. Sci. 63(1), 87-96 (2015). doi:10.1515/bpasts-2015-0010

13. Hoła, B., Schabowicz, K.: Estimation of earthworks execution time cost by means of artificial neural networks. Autom. Constr. 19(5), 570-579 (2010). doi:10.1016/j.autcon.2010.02.004

14. Hoła, J., Sadowski, Ł., Reiner, J., Stach, S.: Usefulness of 3D surface roughness parameters for nondestructive evaluation of pull-off adhesion of concrete layers. Constr. Build. Mater. 84, 111-120 (2015). doi:10.1016/j.conbuildmat.2015.03.014

15. Hoła, J., Sadowski, Ł., Schabowicz, K.: Nondestructive identification of delaminations in concrete floor toppings with acoustic methods. Autom. Constr. 20(7), 799-807 (2011). doi:10.1016/j.autcon.2011.02.002

16. Hoła, J., Książek, M.: Research on usability of sulphur polymer composite for corrosion protection of reinforcing steel in concrete. Arch. Civ. Mech. Eng. 9(1), 47-59. (2009) http://www.acme.pwr.wroc.pl/repository/230/online.pdf 
17. Kamiński, M., Musiał, M., Ubysz, A.: Eigenfrequencies of the reinforced concrete beams-methods of calculations. J. Civ. Eng. Manag. 17(2), 278-283 (2011). doi:10.3846/13923730.2011.576812

18. Kruszyna, Maciej, Rychlewski, Jeremi: Influence of approaching tram on behaviour of pedestrians in signalised crosswalks in Poland. Accid. Anal. Prev. 55, 185-191 (2013)

19. Książek, M.: Use in the building cement composites impregnated with special polymerized sulfur. J. Build. Eng. 4, 255-267 (2015). doi:10.1016/j.jobe.2015.09.007

20. Książek, M.: The experimental research on properties, structures and applies polymer sulfur composites as the industrial waste material in the industry objects. Mater. Struct. 48(10), 3269-3278 (2015). doi:10.1617/s11527-014-0397-1

21. Książek, M.: The experimental research on special polymerized sulfur composite-impregnated concrete and cement mortar. J. Mater. Sci. Eng. 4, 160 (2015). doi:10.4172/2169-0022.1000160

22. Książek, M.: Biological corrosion of the sandstone of the quay of the river of Odra in Wrocław. Eng. Fail. Anal. 44, 338-344 (2014). doi:10.1016/j.engfailanal.2014.05.003

23. Książek, M.: The biocorrosion of city sewer collector impregnated special polymer sulfur binder-polymerized sulfur applied as the industrial waste material. Constr. Build. Mater. 68, 558-564 (2014). doi:10.1016/j.conbuildmat.2014.06.077

24. Książek, M.: The influence of penetrating special polymer sulfur binder-polymerized sulfur applied as the industrial waste material on concrete watertightness. Compos. Part B Eng. 62(62C), 137-142 (2014). doi:10.1016/j.compositesb.2014.02. 027

25. Książek, M.: The evaluate tendencies of corrosion process for reinforcing steel when covered with special polymer sulfur coating. Eng. Fail. Anal. 39, 1-11 (2014). doi:10.1016/j.engfailanal.2014.01.005

26. Książek, M.: The experimental investigations of propriety and applies in the building special coating-sulphur polymer composite as the industrial waste material. Compos. Part B: Eng. 58(58C), 378-385 (2014). doi:10.1016/j.compositesb. 2013.10.087

27. Książek, M.: City sewer collectors biocorrosion. Cent. Eur. J. Eng. 4(4), 398-407 (2014). doi:10.2478/s13531-013-0177-7

28. Książek, M.: The experimental research on properties, structures and applies polymer sulfur composites as the industrial waste material in the industry objects. Mater. Struct. RILEM. (2014). doi:10.1617/s11527-014-0397-1

29. Książek, M.: The intensity of corrosion processes influenced by tensile stress for reinforcing steel covered with sulphur polymer composite applied as industrial waste material. Compos. Part B Eng. 45(1), 1126-1132 (2013). doi:10.1016/j. compositesb.2012.04.072

30. Książek, M.: The experimental and innovative research on intensity of corrosion processes influenced by tensile stress for reinforcing steel covered with sulphur polymer composite applied as industrial waste material. Adv. Sci. Lett. 19(1), 247-251 (2013). doi:10.1166/asl.2013.4652

31. Książek, M.: Experimental research on the surface protection of concrete by polymer sulfur composite. Mag. Concr. Res. 64(10), 945-955 (2012). doi:10.1680/macr.11.00142

32. Książek, M.: The experimental and innovative research on usability of sulphur polymer composite for corrosion protection of reinforcing steel and concrete. Compos. Part B Eng. 42(5), 1084-1096 (2011). doi:10.1016/j.compositesb.2011.03.022

33. Książek, M.: The experimental research on polarization of tensioned rebars coated with sulphur polymer composite. In: 10th Youth Symposium on Experimental Solid Mechanics, Chemnitz, 25th-28th, May 2011, Chemnitz University of Technology. Institute of Mechanics and Thermodynamics. Department of Solid Mechanics, pp. 67-68 (2011)

34. Książek, M.: Experimental research of the intensity of corrosion processes influence by tensile stress for reinforcing steel covered with polymer sulphur composites. In: Concrete Solutions: Proceedings of Concrete Solutions. 4th International Conference on Concrete Repair, Dresden, Germany, 26-28 September 2011, pp. 257-265 (2012)

35. Książek, M.: The mechanical destruction of sulphur composites [Niszczenie mechaniczne kompozytów siarkowych]. Prace Naukowe Instytutu Budownictwa Politechniki Wroclawskiej, ISSN 03249875(80), 105-112 (2001)

36. Książek, M.: The sulphur binders-their potential possibilities of using in buildings [Spoiwa siarkowe - Ich potencjalne możliwości zastosowań w budownictwie]. Prace Naukowe Instytutu Budownictwa Politechniki Wroclawskiej, ISSN: 03249875, Issue 75, CONFERENCE NO. 26, pp. 77-78 (1999)

37. Lowińska-Kluge, A., Błaszczyńskin, T.: The influence of internal corrosion on the durability of concrete. Arch. Civ. Mech. Eng. 12(2), 219-227 (2012). doi:10.1016/j.acme.2012.03.002

38. Łukowski, P.: Rola polimerów w kształtowaniu właściwości spoiw i kompozytów polimerowo-cementowych. Prace Naukowe Politechniki Warszawskiej. Budownictwo 148, 3-159 (2008)

39. Madryas, C.: Forensic investigations of buried utilities failures in Poland. Tunn. Undergr. Sp. Technol. 23(2), 199-205 (2008)

40. Maksymowicz, M., Cruz, P.J.S., Bień, J.: Load capacity of damaged RC slab spans of railway-bridges. Arch. Civ. Mech. Eng. 11(4), 963-978 (2011)

41. Nazarenko, L.V.: Investigation of effective thermoelastic properties of stochastic composite materials. ISSN: 03249875, Issue 75. CONFERENCE NO. 26, 115-122 (1999)

42. Sadowski, L., Nikoo, M.: Corrosion current density prediction in reinforced concrete by imperialist competitive algorithm. Neural Comput. Appl. 25(7-8), 1627-1638 (2014). doi:10.1007/s00521-014-1645-6

43. Sikora, Paweł, et al.: The effect of nanosilica on the mechanical properties of polymer-cement composites (PCC). Proc. Eng. 108, 139-145 (2015)

44. Thomas, C., et al.: Influence of recycled aggregates containing sulphur on properties of recycled aggregate mortar and concrete. Compos. Part B Eng. 45(1), 474-485 (2013). doi:10.1016/j.compositesb.2012.05.019

45. Trapko, T.: Fibre reinforced cementitious matrix confined concrete elements. Mater. Des. 44, 382-391 (2013). doi:10.1016/ j.matdes.2013.09.008

46. Zhang, P.-H., He, J.-J., Zhang, D.-D., Wu, L.-M.: A fault diagnosis method for substation grounding grid based on the square-wave frequency domain model. Metrology and Measurement System 19(1), 63-71 (2012). doi:10.2478/v10178012-0005-z 